\title{
Direct Measurement of Surface Adhesion Between Thin Films of Nanocellulose and Urea- Formaldehyde Resin Adhesives
}

Eko Setio Wibowo

Kyungpook National University

Byung-Dae Park ( $\sim$ byungdae@knu.ac.kr)

Kyungpook National University https://orcid.org/0000-0002-9802-7855

\section{Research Article}

Keywords: UF resins, nanocellulose, adhesion force, work of adhesion, surface energy, van der Waals force

Posted Date: March 11th, 2021

DOI: https://doi.org/10.21203/rs.3.rs-272857/v1

License: (c) (i) This work is licensed under a Creative Commons Attribution 4.0 International License. Read Full License

Version of Record: A version of this preprint was published at Cellulose on July 21st, 2021. See the published version at https://doi.org/10.1007/s10570-021-04088-y. 


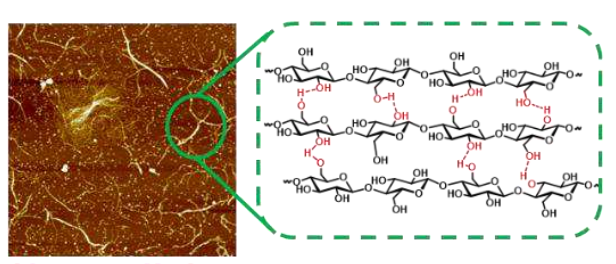

Nanocellulose

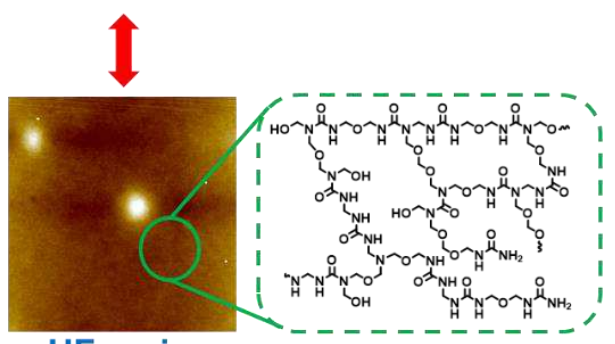

UF resins

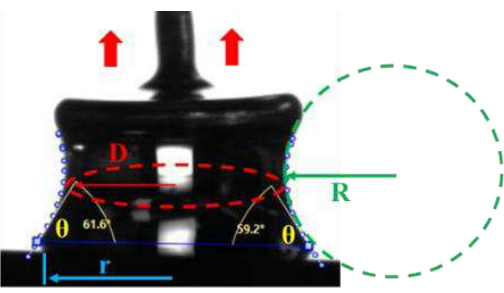

Nanocellulose film-Liquid UF resins

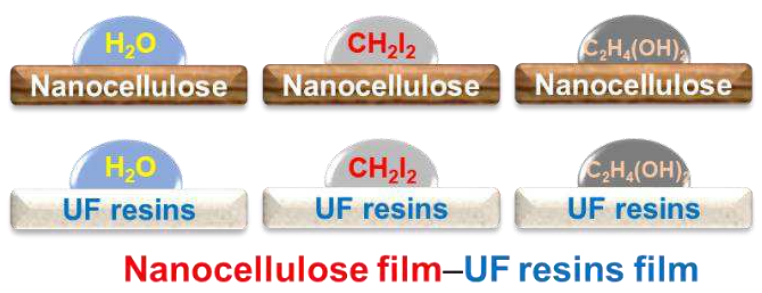


Abstract

10 When applying an adhesive to wood, the chemical heterogeneity of the wood cell walls makes it

11 difficult to understand the contribution they make to the interfacial adhesion between the

12 adhesive and the wood as the adhesion is a very complex physical and chemical phenomenon.

13 This study, for the first time, directly measured the surface adhesion between cellulose, a major

14 component of wood, and urea-formaldehyde (UF) resin adhesives. The adhesion between thin,

15 smooth nanocellulose films, such as cellulose nanofibrils (CNFs), carboxymethylated nanofibrils

16 (CM)-CNFs, and carboxylated cellulose nanocrystals $(\mathrm{C}-\mathrm{CNCs})$, and $\mathrm{UF}$ resins with two

17 formaldehyde to urea $(\mathrm{F} / \mathrm{U})$ molar ratios of 1.0 and 1.6 was measured using two approaches: 1$)$

18 direct measurement of the adhesion force between nanocellulose films and liquid droplets of the

19 UF resins, and 2) calculation of the work of adhesion between films of the nanocelluloses and

20 UF resins using the contact angle and the van Oss-Chaudhury-Good (OCG) method. The results

21 show that the total surface energies, either between the different nanocelluloses or between the

22 two UF resins are somewhat similar, indicating the similarity in their surface properties.

23 However, the adhesion force and work of adhesion of 1.6 UF resins with different types of

24 nanocellulose are higher than those of 1.0 UF resins, which shows that van der Waals forces are

25 dominant in their molecular interactions. These results suggest that the adhesion between 1.6 UF

26 resins and nanocellulose is stronger than that when 1.0 UF resins are used because the 1.6 UF

27 resins have a more branched structure, smoother surface, and higher surface energy.

28 Keywords: UF resins, nanocellulose, adhesion force, work of adhesion, surface energy, van der

29 Waals force

30 *Corresponding author: byungdae@knu.ac.kr 


\section{Introduction}

32 For a long time, wood has been used for many purposes, as a structural material in engineering,

33 as a fuel, and in wood-based panels (Pereira Oliveira Moreira et al. 2020). In terms of wood-

34 based materials, cellulose, a major component of wood, plays a pivotal role in their mechanical

35 properties (Gibson 2012). Engineered wood products such as plywood, particleboard, and

36 medium density fiberboard require adhesives to attach them together, which act as a binder

37 between the wood components. The adhesion process in wood bonding is an extremely complex

38 physical and chemical phenomenon that must be understood to obtain durable and excellent

39 adhesion of wood-based products. One of the primary obstacles in understanding the wood

40 adhesion is the heterogeneity of wood cell walls, which are composed of three major chemical

41 components, cellulose, hemicellulose, and lignin. Despite the role they play in joining wood

42 together, there is a still a lack of understanding about the interaction that occurs between wood

43 adhesives and wood components. To the authors' knowledge, the contribution that these

44 biopolymers make toward wood adhesion is yet unknown. Hence, it is necessary to clarify the

45 contribution that each wood component makes toward the adhesion to have better understanding

46 of wood bonding, which consequently affects the performance of wood-based materials.

47 One of the most extensively used adhesives in wood-based panels is urea-formaldehyde (UF)

48 resin. However, industrial UF resins are known to emit a high amount of formaldehyde, which

49 has led to the necessary reduction of these emissions in industrial settings by decreasing the

50 amount of formaldehyde present in the formulation, with the resulting materials being referred to

51 as low formaldehyde-to-urea (F/U) molar ratio UF resins (Pizzi and Valenzuela 1994; Dunky

52 1998). Unfortunately, in the pursuit of low formaldehyde emissions, the low molar ratio $(\leq 1.0)$

53 UF resins that have previously been prepared show poor adhesion to wood-based panels. 
54 Recently, the crystalline domains in low molar ratio UF resins are responsible for the poor 55 adhesion because they significantly reduce their cohesion by inhibiting the formation of 3D 56 cross-links (Levendis et al. 1992; Wang et al. 2018; Wibowo et al. 2020a; Wibowo and Park

57 2021). Crystalline domains arise because of the formation of hydrogen bonds between linear 58 molecules as a result of oxymethylene and branched methylene ether link cleavage (Wibowo et 59 al. 2020b; Wibowo and Park 2021). This cleavage occurs because of the large amount of urea 60 that requires to be added in the final stage of the synthesis of the UF resins to obtain materials 61 that have low F/U molar ratios. However, high molar ratio $(\geq 1.2)$ UF resins require the addition 62 of only a small amount of urea in the final stage of their preparation, which results in the 63 materials containing more branched molecules rather than their linear counterparts.

64 For decades, researchers have attempted to modify low molar ratio UF resins in various ways 65 to enhance their cross-linking as well as their cohesion (Younesi-Kordkheili et al. 2014; Mahrdt 66 et al. 2016; Esmaeili et al. 2017; Lubis et al. 2017; Wibowo and Park 2020). Typically, the 67 mechanical and physical properties of the materials, such as their internal bonding, tensile shear 68 strength, and thickness swelling, were evaluated to determine the effect that the modification has 69 on the resins. However, the methods used to measure such properties do not directly measure the 70 actual adhesion between wood and resins. The obtained results primarily reflect the combination 71 of the cohesion and adhesion involved in bonding the wood together. Knowledge on the 72 adhesion or interaction between wood and adhesives, particularly UF resins, is essential because 73 the adhesives are responsible for the actual interaction between them, in addition to the cohesion 74 of the adhesives themselves. However, on the one hand, wood cell walls are chemically 75 heterogenous, which makes it difficult to conduct studies on the adhesion, which requires a 76 smooth and homogenous surface (Gustafsson et al. 2012). Nevertheless, model surfaces of the 
77 three primary biopolymers of wood cell wall, cellulose, hemicellulose, and lignin, make it 78 possible to study the adhesion because of the convenient preparation of their smooth and 79 homogenous surfaces (Kontturi et al. 2007; Ahola et al. 2008; Notley and Norgren 2010; 80 Gustafsson et al. 2012; Hoeger et al. 2012; Hollertz et al. 2013; Carrick et al. 2014). Cellulose is 81 the most abundant natural polymer on Earth; it is commonly found in plant cell walls and is a 82 major component of wood (Stelte and Sanadi 2009; Sacui et al. 2014; Zhao et al. 2017). 83 Cellulose is a polysaccharide that is composed of glucose monomers that are typically arranged

84 in linear chains that are bound together via inter- and intramolecular hydrogen bonds (He et al. 85 2020; Tang et al. 2021). As mentioned above, cellulose is one of the most important wood 86 biopolymers because of its presence being correlated with the strength of wood. Thus, this study 87 is focused on the direct measurement of adhesion between cellulose, the major component of the 88 wood cell wall, and the most extensively used wood adhesives, UF resins, which are prepared 89 with two different F/U molar ratios of 1.0 and 1.6. To this aim, three types of nanocellulose are 90 used in this study, namely, cellulose nanofibrils (CNFs), carboxymethylated nanofibrils (CM)91 CNFs, and carboxylated cellulose nanocrystals (C-CNCs).

92 Generally, smooth and thin cellulose films that are suitable for wettability and adhesion studies 93 are prepared using spin-coating or layer-by-layer (LbL) deposition methods (Lefebvre and Gray 94 2005; Kontturi et al. 2007, 2011; Ahola et al. 2008; Karabulut et al. 2012; Qi et al. 2012). For 95 example, Ahola et al. prepared cellulose model films from both low and high charge density 96 nanofibrils using a spin-coating method (Ahola et al. 2008). The results demonstrated that the 97 charge density of the model surfaces affects their morphology, leading to average root mean 98 squared (rms) roughness values of 4 and $2 \mathrm{~nm}$, for low and high charge density nanofibrils, 99 respectively. Furthermore, Karabulut et al. prepared smooth $\mathrm{CM}-\mathrm{CNFs}$ films using a layer-by- 
100 layer method (Karabulut et al. 2012). They fabricated pure CM-CNFs and hybrid conjugates of 101 CM-CNF-dopamine films, which combine with polyethyleneimine (PEI) as an anchoring 102 polyelectrolyte, to form smooth surfaces with average rms roughness values of 5 and $8 \mathrm{~nm}$, for 103 the pure $\mathrm{CM}-\mathrm{CNFs}$ and hybrid $\mathrm{CM}-\mathrm{CNFs}$, respectively.

104 Usually, the interfacial adhesion of a cellulose model surface is measured using 105 Johnson-Kendall-Roberts (JKR) contact mechanics, contact angle measurements, and more 106 advanced methods such as atomic force microscopy (AFM) in the peak-force mode (Rundlöf et 107 al. 2000; Eriksson et al. 2007; Gustafsson et al. 2012; Carrick et al. 2014; Lai et al. 2019). For 108 example, Gustafsson et al. measured the work of adhesion between cellulose and other wood 109 biopolymers using the JKR method and contact angle measurements (Gustafsson et al. 2012). 110 They reported that the JKR work of adhesion was lower than that calculated from contact angle 111 measurements because of the overestimation of the surface energies of the contact angle 112 measurements. Furthermore, Lai et al. compared the JKR contact mechanics and AFM peak113 force mode measurements combined with a colloidal probe technique to measure the interfacial 114 adhesion between cellulose surfaces (Lai et al. 2019). They reported that the JKR adhesion 115 values are higher than their proposed experimental values because the JKR model only considers 116 the interactions between smooth surfaces at equilibrium, whereas their developed method 117 considers a contact model of rough-rough interactions, devised by dividing the surface contacts 118 into primary and secondary levels. Hence, the local individual contacts between rough surfaces 119 were considered in their work.

120 However, in this study, the direct adhesion between nanocellulose and UF resins is determined 121 by measuring the adhesion force(Sun et al. 2017; Wang et al. 2020a) between nanocellulose 122 films and liquid droplets of the UF resins, as well as by calculating the work of adhesion between 
123 the films of the nanocelluloses and UF resins using contact angles via the van

124 Oss-Chaudhury-Good (OCG) method (van Oss et al. 1988; Gustafsson et al. 2012). These two

125 methods were selected because of their convenience and simplicity. The adhesion force $(F)$

126 between the UF resin droplets and nanocellulose films can be calculated using Eq. 1. $F$

127 comprises two components: i) the surface tension force $\left(F_{s}\right)$, which is the vertical component of

128 the liquid-gas interfacial tension located along the perimeter of the triple contact line, and ii) the

129 other is the capillary pressure force $\left(F_{L}\right)$, which is caused by the curvature of the liquid because

130 of the pressure difference (Eq. 2) across the liquid-gas interface for a stretched droplet (see

131 Scheme 1 for details). The combination of these two forces can be expressed using the following

132 equation (Sun et al. 2017; Wang et al. 2020a):

$$
F=F_{S}-F_{L}=2 \pi r \gamma \sin \theta-\pi r^{2} \Delta P
$$

134 where $r$ is the base radius of a droplet that is in contact with the substrate, $\gamma$ is the liquid-gas

135 interfacial tension, $\theta$ is the contact angle, and $\Delta P$ is the Laplace pressure, defined as the pressure 136 difference inside and outside the droplet. Note that $\Delta P$ can be either positive or negative, 137 depending on the shape of the droplet. The contact angle at the maximum adhesion force $\left(F_{\max }\right)$ is 138 the most stable contact angle, $\theta_{\max }$. All the stretched droplets are concave shaped; thus, $\Delta P$ can be 139 expressed as follows:

$$
\Delta P=\gamma\left(\frac{1}{D}-\frac{1}{R}\right)
$$

141 where $D$ and $R$ are the principal radii of the droplet. 


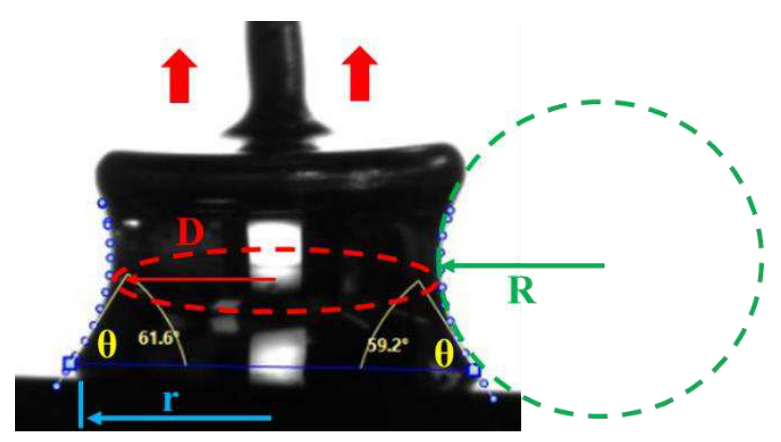

143 Scheme 1. An example of a UF resin droplet in its maximum adhesion state recorded at the 144 retraction stage, where the contact angle $(\theta)$, droplet base radius $(r)$, and principal radii $(D$ and $R)$ 145 of the droplet are shown.

146 The work of adhesion between these two films can be calculated using the surface energy of each 147 film, which can be determined using the OCG method. The surface energies of the different 148 nanocelluloses and UF resin films were calculated according to the OCG method (van Oss et al. 149 1988; Gustafsson et al. 2012) (Eq. 3):

$$
\gamma_{l, i}^{T o t}\left(1+\cos \theta_{i}\right)=2\left(\sqrt{\gamma_{l, i}^{L W} \gamma_{s}^{L W}}+\sqrt{\gamma_{l, i}^{+} \gamma_{s}^{-}}+\sqrt{\gamma_{l, i}^{-} \gamma_{s}^{+}}\right)
$$

151 where $\theta$ is the contact angle between a droplet of a liquid and a solid; $\gamma^{T o t}$ is the total surface 152 energy; $\gamma^{L W}$ is the Lifshitz-van der Waals (dispersive) component of the surface energy; $\gamma^{+}$is the 153 electron acceptor surface energy parameter; and $\gamma^{-}$is the electron donor surface energy 154 parameter of the material. Hence, this method allows the surface energy to be split into its 155 dispersive, $\gamma^{L W}$; and polar component, acid, $\gamma^{+}$, and base, $\gamma^{-}$, contributions. Because the OCG 156 equation contains three unknown variables $\left(\gamma_{s}^{L W}, \gamma_{s}^{+}\right.$, and $\left.\gamma_{s}^{-}\right)$, this method requires the use of a 157 minimum of three test liquids that have known surface tensions to solve the equation. As shown 158 in Scheme 2, water, diiodomethane, and ethylene glycol are commonly used for this purpose. 


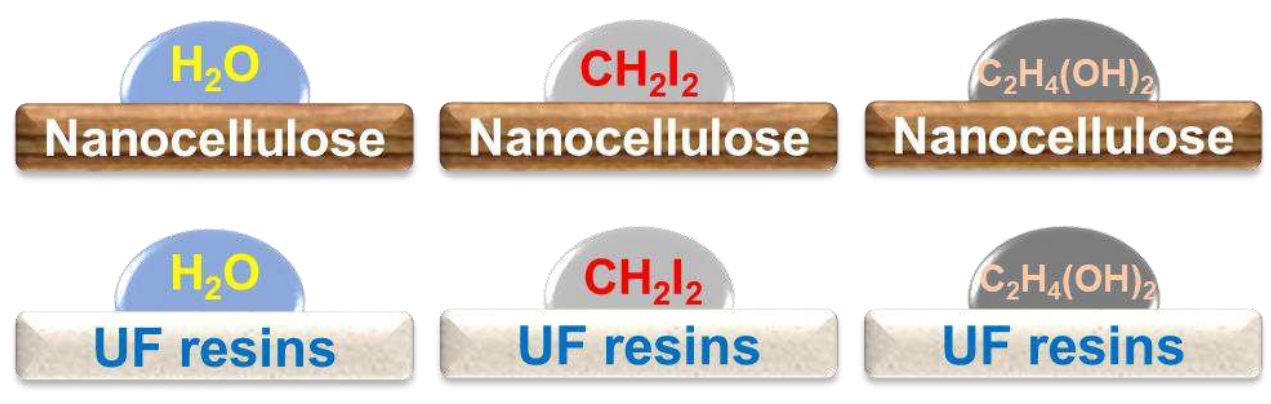

160

161 Scheme 2. Schematic of the measuring of contact angles on nanocellulose and UF resin films 162 using the probe liquids in the OCG method.

164 Furthermore, AFM and X-ray photoelectron spectroscopy (XPS) were used to determine the 165 thickness, surface roughness, and chemical composition of the sample films. Moreover, Fourier 166 transform infrared spectroscopy (FTIR), X-ray diffraction (XRD), and transmission electron 167 microscopy (TEM) were also used to determine the chemical structures, diffraction patterns, and 168 morphologies of the different nanocellulose samples, whereas gel permeation chromatography 169 (GPC) was used to determine the molecular weights of the low and high molar ratio UF resins.

1712 Experimental

\section{$172 \quad 2.1$ Materials}

173 Formalin (37 wt $\%$ ) and extra pure grade urea (99 wt\%) were obtained from Daejung Chemical,

174 Korea. Extra pure grade $\mathrm{NH}_{4} \mathrm{Cl}(99 \mathrm{wt} \%), \mathrm{NaOH}(93 \mathrm{wt} \%)$, and aqueous formic acid ( $\left.85 \mathrm{wt} \%\right)$

175 were purchased from Duksan Chemical, Korea. High-performance liquid chromatography 176 (HPLC) grade dimethylformamide (DMF, 99.9\%) and dimethyl sulfoxide (DMSO, 99.9\%) used 177 as the mobile phase for GPC analysis were obtained from Fisher Scientific and Duksan Chemical 178 Korea, respectively. CNFs ( $1 \mathrm{wt} \%)$ and CM-CNFs (2 wt $\%)$ with a degree of substitution of 0.8 $179 \mathrm{mmol} / \mathrm{g}$ were obtained from CNNT Co. Ltd in Suwon, Korea and Moorim Paper in Ulsan, Korea, 
180 respectively. $\mathrm{C}-\mathrm{CNCs}(0.45 \mathrm{wt} \%)$ with a degree of oxidation of 0.15 were prepared in the

181 laboratory as per a previously reported method (Khanjanzadeh and Park 2021). CNFs were

182 prepared using an aqueous counter collision method(Kondo et al. 2014), while both the

$183 \mathrm{CM}-\mathrm{CNFs}$ and $\mathrm{C}-\mathrm{CNCs}$ were prepared via a chemical treatment (Gustafsson et al. 2012;

184 Khanjanzadeh and Park 2021). Silicon wafer (p-type, Si 100 with a native oxide layer on top)

185 was acquired from MTI Korea, Seoul, Korea. Hellmanex ${ }^{\text {TM }}$ III solution and 186 poly(diallyldimethylammonium chloride) (PDADMAC) solution $(20 \mathrm{wt} \%)$ with an average

187 molecular weight of 200,000-350,000 was purchased from Sigma-Aldrich, USA. Moreover,

188 HPLC-grade water, diiodomethane (99\%), and ethylene glycol (99.8\%) were purchased from

189 Sigma-Aldrich, USA, and used in the contact angle measurements.

190

\section{$191 \quad 2.2$ Synthesis of UF resins with different molar ratios}

192 Low and high F/U molar ratio (1.0 and 1.6) UF resins were prepared via an 193 alkaline-acid-alkaline three-step reaction. Formalin solution was first poured into a four-neck

194 glass reactor, adjusted to $\mathrm{pH} 8.0$ using sodium hydroxide ( $\mathrm{NaOH}, 20 \mathrm{wt} \%$ ), and then heated to $19540{ }^{\circ} \mathrm{C}$. Urea was subsequently added into the reactor to give an initial $\mathrm{F} / \mathrm{U}$ molar ratio of 2.0. The 196 mixture was then heated to $90{ }^{\circ} \mathrm{C}$ and the $\mathrm{pH}$ was maintained at 8.0 for $1 \mathrm{~h}$ to allow the addition 197 reaction to proceed. Then, the temperature and $\mathrm{pH}$ were adjusted to $80^{\circ} \mathrm{C}$ and 4.6 , respectively, 198 to facilitate the condensation reaction. The reaction was terminated when a target viscosity of ' $J$ 199 K' scale was reached based on readings using a bubble viscometer (VG 900, Gardener-Holdt, 200 Columbia, South Carolina, USA) and the $\mathrm{pH}$ was adjusted back to alkaline (8.0-8.2).

201 Furthermore, a certain amount of urea was added into the glass reactor to obtain a final F/U 202 molar ratio of 1.0 or 1.6 and the temperature was maintained at $60{ }^{\circ} \mathrm{C}$ for $20 \mathrm{~min}$. Subsequently, 
203 the resins were cooled to $25^{\circ} \mathrm{C}$ and the $\mathrm{pH}$ was adjusted to $\sim 8.2$. The resins were then stored at 204 room temperature for $24 \mathrm{~h}$ prior to their analysis.

\subsection{Properties of the UF resins}

207 The viscosity, non-volatile solid content, and gelation time of the UF resins with different molar 208 ratios of 1.0 and 1.6 were determined as per a method used in a previous work (Wibowo et al. 209 2020a). The apparent molecular weights of the 1.0 and 1.6 UF resins were measured using GPC 210 (YL9100, Younglin, Gyeonggido, Korea). Note that 1\% UF resin solutions were prepared by 211 dissolving each sample in a mixture of 10\% DMSO and 90\% DMF and placing them in an oven

212 at $50{ }^{\circ} \mathrm{C}$ for $3 \mathrm{~h}$. Subsequently, the mixtures were injected into the GPC instrument after 213 filtration through a $0.45-\mu \mathrm{m}$-sized filter. The columns used in this characterization technique 214 were KD 801, 802, and 806 M (SHODEX, Showa Denko K.K., Tokyo, Japan). Polyethylene 215 glycol (PEG) with a molecular weight $\left(\mathrm{Mw}_{\mathrm{w}}\right)$ of between 106 and 25,200 Da (Polymer Standards 216 Service $\mathrm{GmbH}$, Mainz, Germany) was used for calibration standards. The weight-averaged $\mathrm{M}_{\mathrm{w}}$, 217 number molecular weight $\left(\mathrm{M}_{\mathrm{n}}\right)$, and polydispersity index (PDI) of the resins were calculated 218 using the YL-Clarity Version 6.1.0.130 software (Younglin, Gyenggi-do, Korea).

\section{$220 \quad 2.4$ Attenuated total reflection-FTIR (ATR-FTIR) spectroscopy}

221 ATR-FTIR measurements were conducted using a Bruker Alpha FTIR spectrometer (Bruker 222 Optics $\mathrm{GmbH}$, Ettlingen, Germany) to determine the functional groups of the different CNFs, 223 CM-CNFs, and C-CNCs nanocellulose samples. Solid suspensions of each of the nanocellulose 224 materials were freeze-dried, ground into a fine powder, and then measured using the 
225 spectrometer for 32 scans in the wavelength range of $400-4000 \mathrm{~cm}^{-1}$ at a resolution of $4 \mathrm{~cm}^{-1}$.

226 The spectrum of each sample was then normalized using a min-max normalization.

\section{$228 \quad 2.5$ X-ray diffraction (XRD) analysis}

229 XRD patterns of the different CNFs, CM-CNFs, and C-CNCs nanocellulose samples were 230 analyzed using a multipurpose diffractometer (Malvern Panalytical, UK) equipped with a $\mathrm{CuK} \alpha$ 231 radiation source $(\lambda=0.15406 \mathrm{~nm})$. For analysis, the solid suspensions of the different 232 nanocellulose materials were freeze-dried and ground into a fine powder. These samples were 233 then scanned at room temperature from $0^{\circ}$ to $50^{\circ}$ with a step of $0.02^{\circ} / \mathrm{min}$. Moreover, the 234 crystallinity of the samples was estimated using the peak deconvolution method from XRD 235 patterns. The sharp crystalline peaks in the patterns correspond to cellulose I reflections $\left(\begin{array}{lll}1 & 1 & 0\end{array}\right)$, 236 ( $1-10),\left(\begin{array}{lll}0 & 1 & 2\end{array}\right)$, and $\left(\begin{array}{lll}2 & 0 & 0\end{array}\right)$, and the broad peak corresponding to amorphous material were 237 fitted using a pseudo-Voigt function instead of the commonly used Gaussian function. As 238 pointed out by French et al., the simple and very broad Gaussian peak does not adequately 239 represent amorphous cellulose (Ling et al. 2019; French 2020). In addition, the curve

240 deconvolution representation of the amorphous fraction cannot reach the minimum intensity of 241 the observed data at about $18.5^{\circ}$. Furthermore, the crystallinity of each sample was calculated as 242 follows:

$$
\text { Crystallinity }(\%)=\frac{S c}{S t} \times 100
$$

244 where $S c$ represents the area of the crystalline domain and $S t$ is the area of the total domain 245 (crystalline + amorphous). 
248 The morphologies of the CNFs, CM-CNFs, and C-CNCs were analyzed using TEM (JEM-2100

249 F, JEOL, Japan), where the samples were prepared using a previously described method

250 (Khanjanzadeh and Park 2021). Briefly, each sample was diluted with water to a concentration of

$2510.01 \mathrm{wt} \%$. Then, small amounts of the diluted samples were dropped on copper grids and dried at

252 room temperature. Subsequently, the samples were stained by placing a drop of $3 \%$ uranyl

253 acetate solution on the grids to intensify the contrasts of the images. Any excess stain solution

254 was absorbed using filter paper and the samples were then left to dry at room temperature.

255

$256 \quad 2.7$ Atomic force microscopy

257 Prior to AFM analysis, different UF resins and nanocellulose films were first prepared using a 258 spin-coating method. Briefly, Si wafers were cut to a size of $1 \times 1 \mathrm{~cm}^{2}$ and cleaned with $2 \%$

259 Hellmanex solution at room temperature for $120 \mathrm{~min}$. The Si substrates were then rinsed in

260 deionized water and dried inside a clean desiccator in a fume hood. The cleaned substrates were

261 then placed in $0.1 \%$ PDADMAC for $1 \mathrm{~h}$. Subsequently, the pre-treated substrates were rinsed in

262 deionized water and dried inside a clean desiccator in a fume hood. Finally, 1.0 or 1.6 UF resins

263 mixed with 0 or $3 \% \mathrm{NH}_{4} \mathrm{Cl}$ and $0.1 \mathrm{wt} \%$ of the $\mathrm{CNFs}, \mathrm{CM}-\mathrm{CNFs}$, and $\mathrm{C}-\mathrm{CNCs}$ nanocellulose

264 samples were spin-coated onto the Si wafer substrates at $3000 \mathrm{rpm}$ for $30 \mathrm{~s}$. Furthermore, the

265 resins films were then cured at $105^{\circ} \mathrm{C}$ for $3 \mathrm{~h}$ in an oven, whereas the nanocellulose films were

266 dried at $50{ }^{\circ} \mathrm{C}$ for $3 \mathrm{~h}$. The morphologies of all the sample surfaces were then imaged using AFM

267 (Park NX20, Park Systems Corp., Suwon, Korea). Images were acquired in non-contact mode at

268 a nominal resonance frequency of $290.5 \mathrm{kHz}$, a Q-factor of 574.8 , a scan rate of $1.00 \mathrm{~Hz}$, and a

269 set-point of $7.0 \mathrm{~nm}$. The rms surface roughness $\left(R_{q}\right)$ was calculated from the average of six $10 \times$

$27010 \mu \mathrm{m}$ areas using XEI software (4.3.4 version, Park Systems Corp.). The thickness of films is 
271 determined by measuring the height difference between the top surface of the sample film and

272 the Si substrate surface at four different locations (Yokota et al. 2007). Thus, the film thickness

273 was measured at two locations, namely, the edge and middle of the films. To measure the middle

274 thickness, a section of the films was scratched off with the tip of a pair of tweezers wrapped in

275 tissue that was dipped in $1 \mathrm{~N} \mathrm{HCl}$ prior to their use (Sczech and Riegler 2006). AFM images

276 showing the thickness measurements are provided in the supplementary information (Fig. S1).

277

$278 \quad 2.8$ XPS analysis

279 An XPS system (Nexsa, Thermo Fisher Scientific, Massachusetts, USA) was used to determine

280 the chemical compositions of the different nanocellulose model surfaces. For quantitative

281 elemental analysis, low-resolution scans at a pass energy of $80 \mathrm{eV}$ and $1 \mathrm{eV}$ steps were used to

282 analysis the $\mathrm{C}_{1 \mathrm{~s}}, \mathrm{O}_{1 \mathrm{~s}}$, and $\mathrm{Si}_{2 \mathrm{p}}$ regions, whereas high-resolution scans at a pass energy of $20 \mathrm{eV}$

283 and $0.1 \mathrm{eV}$ steps were used to obtain detailed chemical analysis of the samples (Ahola et al.

284 2008). High-resolution XPS spectra were used to deconvolute the $\mathrm{C}-\mathrm{C}, \mathrm{C}-\mathrm{O}, \mathrm{O}-\mathrm{C}-\mathrm{O}$, and $\mathrm{O}-$

$285 \mathrm{C}=\mathrm{O}$ peaks using a Gaussian function.

\section{$287 \quad 2.9$ Maximum adhesion force and work of adhesion measurements}

288 The maximum adhesion force $\left(F_{\max }\right)$ values of droplets of the UF resins with different molar 289 ratios on the different nanocellulose films were measured using a tensiometer (DCAT 25, Data 290 Physics Instruments GmbH, Filderstadt, Germany). For measurements, a liquid droplet was 291 placed on an RG 2 Du Noüy ring and pressed onto the respective solid film surface. Then, the 292 liquid droplet was pulled off and a force-distance curve was recorded automatically during this 293 procedure. The surface of a film sample was moved upward toward the UF resin droplet at a 
294 speed of $0.5 \mathrm{~mm} / \mathrm{s}$, which was then reduced to $0.2 \mathrm{~mm} / \mathrm{s}$ when the film sample surface came into 295 contacted with the surface of the droplet. After reaching the compression distance $(0.1 \mathrm{~mm})$, the 296 film sample was retracted at a constant speed of $0.2 \mathrm{~mm} / \mathrm{s}$ until the droplet was detached from

297 the surface of the film sample. $F_{\max }$ was measured at the $\theta_{\max }$ identified from a typical recorded 298 image (Scheme 1) and represented by the peak of a force-distance plot. Then, the $F_{\max }$ value was

299 calculated based on Eq 1. This experiment was repeated three times for each sample. 300 Furthermore, the work of adhesion $\left(W_{12}\right)$ between the nanocellulose and UF resin films was 301 calculated using the following equation(Gustafsson et al. 2012; Carrick et al. 2014):

$$
W_{12}=2\left(\sqrt{\gamma_{1}^{L W} \gamma_{2}^{L W}}+\sqrt{\gamma_{1}^{+} \gamma_{2}^{-}}+\sqrt{\gamma_{1}^{-} \gamma_{2}^{+}}\right)
$$

303 where $\gamma_{1}$ and $\gamma_{2}$ are the surface energies of the nanocellulose and UF resin films, respectively, 304 which were determined using the OCG method and from contact angles (Eq 3). Static contact 305 angle measurements were performed using the same tensiometer, using HPLC-grade water, 306 diiodomethane, and ethylene glycol. The contact angles were measured using the sessile drop 307 method, with the measurements repeated three times for each sample. The reported contact 308 angles were recorded after at least $20 \mathrm{~s}$ to obtain values that were as stable as possible without 309 any significant influence from the penetration of the liquid into the film (Gustafsson et al. 2012;

310 Carrick et al. 2014). The contact angles were used to calculate the surface energies of the 311 nanocellulose and UF resin samples according to the OCG method(van Oss et al. 1988) (Eq 3).

312 The surface tensions, including the dispersive, acid, and base components, of the three probe 313 liquids used in this experiment were obtained from the literature (van Oss 1993; Cwikel et al. 314 2010; Jafarzadeh et al. 2011). 
316 Table 1. The surface energies $\left(\mathrm{mJ} \mathrm{m}^{-2}\right)$ of the three liquids used for the contact angle

317 measurements (van Oss 1993; Cwikel et al. 2010; Jafarzadeh et al. 2011).

\begin{tabular}{llllll}
\hline Probe liquid & $\gamma^{\text {Tot }}$ & $\gamma^{L W}$ & $\gamma^{A B}$ & $\gamma^{+}$ & $\gamma^{-}$ \\
\hline Diiodomethane & 50.8 & 50.8 & 0 & 0 & 0 \\
Water & 72.8 & 21.8 & 51 & 25.5 & 25.5 \\
Ethylene glycol & 48 & 29 & 19 & 1.92 & 47 \\
\hline
\end{tabular}

\section{3. Results and Discussion}

\section{$320 \quad 3.1$ Physical and chemical properties of the UF resins and nanocellulose samples}

321 The properties and characteristics of the UF resins are closely related to their $\mathrm{F} / \mathrm{U}$ molar ratio.

322 Usually, high F/U molar ratio UF resins have better properties than those with lower ratios, as

323 has been explained in many reports published in the literature (Park and Jeong 2011; Park et al.

324 2013; Wibowo et al. 2020a). As presented in Table 2, the viscosities and molecular weights of

325 the samples increase as their molar ratios increase from 1.0 to 1.6 , indicating that the $1.6 \mathrm{UF}$

326 resin contains bigger molecules than the $1.0 \mathrm{UF}$ resin, which is primarily attributed to the

327 formation of more branched molecules in the former. The amount of urea added at the end of the

328 synthesis procedure, particularly in the case of the 1.0 UF resin, results in the formation of linear

329 molecules that have a low viscosity and molecular weight. It has been revealed that the addition

330 of an excess of urea to the synthesis under the alkaline condition might split oxymethylene and

331 branched methylene ether linkages into linear molecules in the UF resins (Wibowo et al. 2020b;

332 Wibowo and Park 2021). The formation of linear molecules contributes to the crystalline

333 domains because they are responsible for the ordered arrangement, maintained by hydrogen 
334 bonds that form between the linear molecules, as has been reported in a previous work (Wibowo

335 et al. 2020a; Wibowo and Park 2021). These crystalline domains inhibit the formation of a 3D

336 network and consequently decrease the reactivity and adhesion of the UF resins. The degradation

337 in the reactivity of the resin of the sample with a $\mathrm{F} / \mathrm{U}$ molar ratio of 1.0 was demonstrated by a

338 significant increase in its gelation time compared with that of the resin with a $1.6 \mathrm{~F} / \mathrm{U}$ molar

339 ratio. Moreover, the high amount of free formaldehyde present in the 1.6 UF resin is capable of

340 facilitating the curing of the sample, thus resulting in a shorter gelation time, because it acts as a

341 bridge that connects the oligomers formed in the pre-cured resin (Wibowo and Park 2020).

343 Table 2. Properties of the two UF resins with different F/U molar ratios.

\begin{tabular}{ccccccccc}
\hline $\begin{array}{c}\mathrm{F} / \mathrm{U} \\
\text { molar } \\
\text { ratio }\end{array}$ & $\begin{array}{c}\text { Non-volatile } \\
\text { solids content } \\
(\%)\end{array}$ & $\mathrm{pH}$ & $\begin{array}{c}\text { Specific } \\
\text { gravity }\end{array}$ & $\begin{array}{c}\text { Gelation } \\
\text { time }(\mathrm{s})\end{array}$ & $\begin{array}{c}\text { Viscosity } \\
(\mathrm{mPa})\end{array}$ & $\begin{array}{c}\mathrm{Mw} \\
(\mathrm{g} / \mathrm{mol})\end{array}$ & $\begin{array}{c}\mathrm{Mn} \\
(\mathrm{g} / \mathrm{mol})\end{array}$ & PDI \\
\hline 1.0 & $57.9 \pm 0.2$ & 8.1 & 1.21 & $145.0 \pm 1.0$ & $147.5 \pm 1.1$ & 578 & 369 & 1.56 \\
1.6 & $53.0 \pm 0.3$ & 8.3 & 1.20 & $57.3 \pm 1.0$ & $215.0 \pm 1.0$ & 762 & 475 & 1.60 \\
\hline
\end{tabular}

345 To understand the adhesion between a UF resin and cellulose, the chemical properties of the 346 cellulose need to be understood. Thus, different types of nanocellulose were characterized to 347 evaluate the influence of chemical property and morphology to their surface adhesion with UF 348 resins. Fig. 1 shows the FTIR spectra and XRD patterns of the different nanocellulose samples. It 349 can be seen that the functional groups in the $\mathrm{CNFs}, \mathrm{CM}-\mathrm{CNFs}$, and $\mathrm{C}-\mathrm{CNCs}$ samples are 350 somewhat similar. For example, they all feature a broad hydroxyl peak at $3600-3000 \mathrm{~cm}^{-1}$ in

351 their FTIR spectra, as they primarily comprise hydrogen-bonded hydroxyl groups (Leng and Pan 352 2019). However, in the case of the CM-CNFs, the FTIR peak shapes are different and of a lower 
353 intensity compared with those of the other samples, indicating that it has fewer - $\mathrm{OH}$ groups due

354 to these being replaced with negatively charged carboxymethyl groups $\left(-\mathrm{CH}_{3} \mathrm{COO}^{-}\right)$, which can

355 separate some hydrogen bonds via a charge repulsion effect. Another notable difference can be

356 observed in the FTIR spectra at $\sim 1640-1590 \mathrm{~cm}^{-1}$. Typical asymmetric $\left(1590 \mathrm{~cm}^{-1}\right)$ (Dos Santos

357 et al. 2015; Melilli et al. 2020; Wu et al. 2021) and symmetric (1420 and $\left.1217 \mathrm{~cm}^{-1}\right)($ Melilli et

358 al. 2020) vibrations associated with the carboxylate anion $\left(\mathrm{COO}^{-}\right)$were detected in the spectra of

359 both the CM-CNFs and C-CNCs samples, while only a weak band at $1640 \mathrm{~cm}^{-1}$ attributed to $\mathrm{OH}$

360 bending(Leng and Pan 2019) was observed in the spectrum of the CNFs. Nonetheless, OH

361 bending was still detected and overlapped at the shoulder of the spectrum of the CM-CNFs,

362 indicating that there are still certain similarities between the CNFs and CM-CNFs, with their

363 only difference being in the abundance of negative charges. Interestingly, the absorption bands at

$364 \sim 1107 \mathrm{~cm}^{-1}$ (anhydroglucose ring vibration) and $1053 \mathrm{~cm}^{-1}(\mathrm{C}-\mathrm{O}-\mathrm{C}$ pyranose ring vibration) in

365 the FTIR spectrum of the $\mathrm{C}-\mathrm{CNCs}$ are more intense than those observed for the other samples,

366 indicating that certain non-cellulosic amorphous material was removed during the oxidation of

367 the samples, which consequently increased the crystalline cellulose content (Khanjanzadeh and

368 Park 2021). These bands are of very weak intensity in the spectrum of the CM-CNFs, indicating

369 that it may feature fewer crystalline domains. These results are supported by the XRD and

370 crystallinity data shown in Fig. 1b-c. The XRD patterns of the nanocellulose samples feature

371 four crystalline peaks associated with the (lll $\left.\begin{array}{lll}1 & 1 & 0\end{array}\right),\left(\begin{array}{lll}1 & -1 & 0\end{array}\right),\left(\begin{array}{lll}0 & 1 & 2\end{array}\right)$, and $\left(\begin{array}{lll}2 & 0 & 0\end{array}\right)$ reflections

372 typically associated with cellulose I and one broad peak at a $2 \theta$ angle of $\sim 18^{\circ}$ that can be

373 attributed to an amorphous region (Nindiyasari et al. 2016). However, the peaks at $\sim 12^{\circ}$ and

$374 \sim 20^{\circ}$ in the XRD pattern of the CM-CNFs are more intense in comparison, and are indicative of

375 the cellulose II crystalline structure of the CM-CNFs (Bhandari et al. 2012). It thus appears that 
376 some cellulose I has been converted to cellulose II and amorphous. However, the pattern of CM-

377 CNFs is still dominated by the cellulose I reflections which is consistent with FTIR result.

378 Furthermore, the $\mathrm{C}-\mathrm{CNCs}$ have the highest crystallinity compared with the other samples,

379 observed from its XRD pattern having the lowest intensity of the amorphous peak. This occurs

380 because the strong acid used during the preparation of the $\mathrm{C}-\mathrm{CNCs}$ removes most of the

381 amorphous material from the sample, resulting in the presence of highly crystalline cellulose, as

382 illustrated in Scheme 3. However, the CM-CNFs exhibit the lowest crystallinity, with its XRD

383 pattern featuring the amorphous peak with the highest intensity. As mentioned in the FTIR

384 results, the CM-CNFs may still contain some noncellulosic amorphous material. Moreover,

385 another reason for the low crystallinity of this sample is the high degree of substitution of the

386 carboxymethyl groups in the CM-CNFs, which contributes to the negative charge that induces

387 electrostatic repulsion in this material. This leads to the destruction of hydrogen bonds, resulting

388 in the CM-CNFs having a less ordered structure, as shown in Scheme 3. This result is in

389 agreement with the published results of many studies in the literature, which report that the

390 incorporation of carboxymethyl groups in a sample reduces the crystallinity of the cellulose

391 (Bhandari et al. 2012; Doh et al. 2013; Dos Santos et al. 2015).

392 

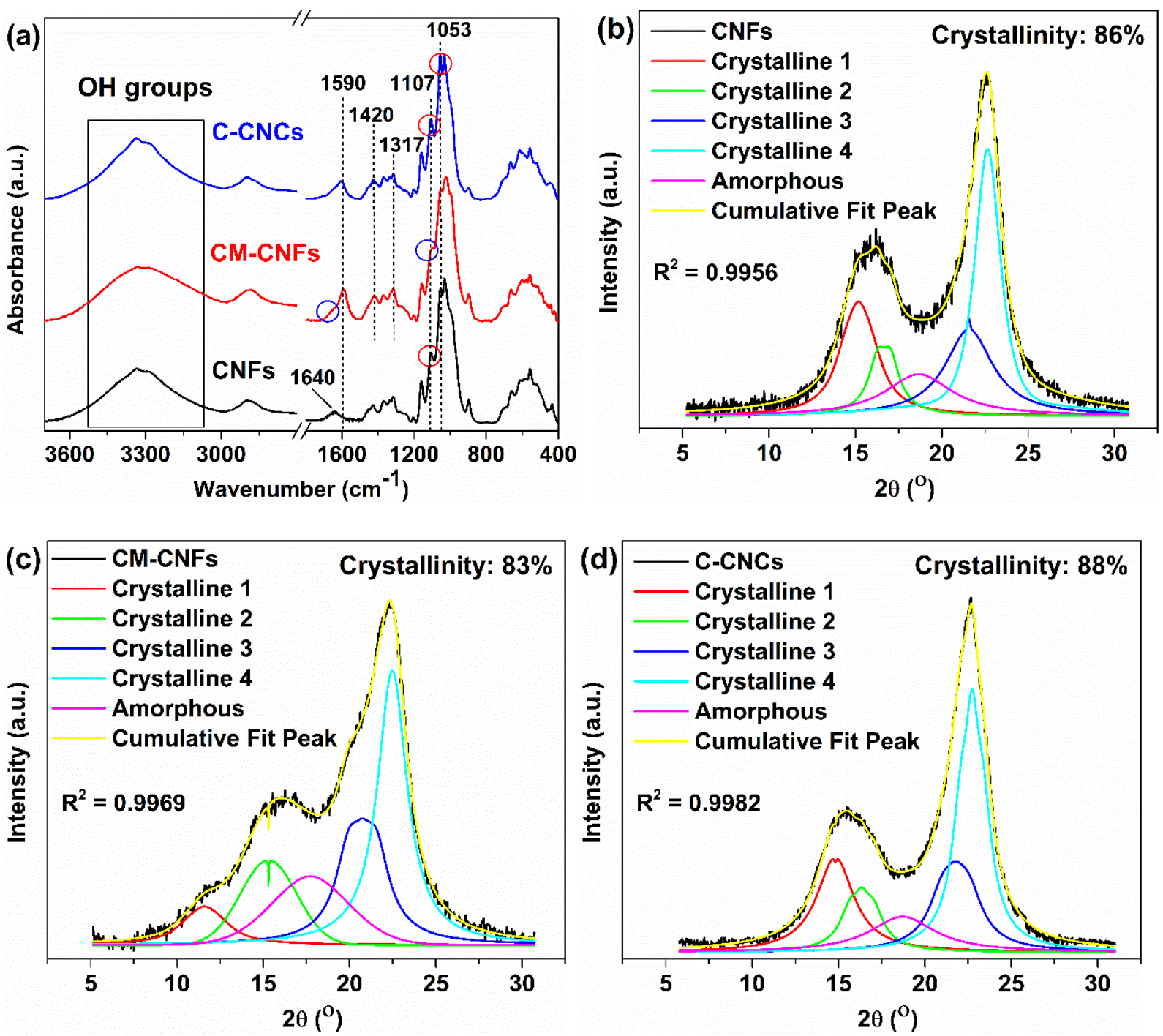

Fig. 1. (a) FTIR spectra and deconvoluted XRD patterns of the (b) CNFs, (c) CM-CNFs, and (d) C-CNCs.

398 Scheme 3 shows the schematic of the structures of the nanocellulose samples alongside their

399 actual morphology exhibited in TEM images. The TEM images (Scheme 3 and Fig. S2) clearly 400 show the differences in the morphologies of the nanocellulose samples, particularly in their 401 shape and size. For instance, the CNFs exhibit large web-like and highly entangled structures, 402 while the CM-CNFs are relatively short and separated fibrils. Moreover, the TEM image of the 
404 results, similar morphologies of nanocelluloses in the TEM images of different cellulose samples

405 were observed in another report in the literature (Xu et al. 2013).

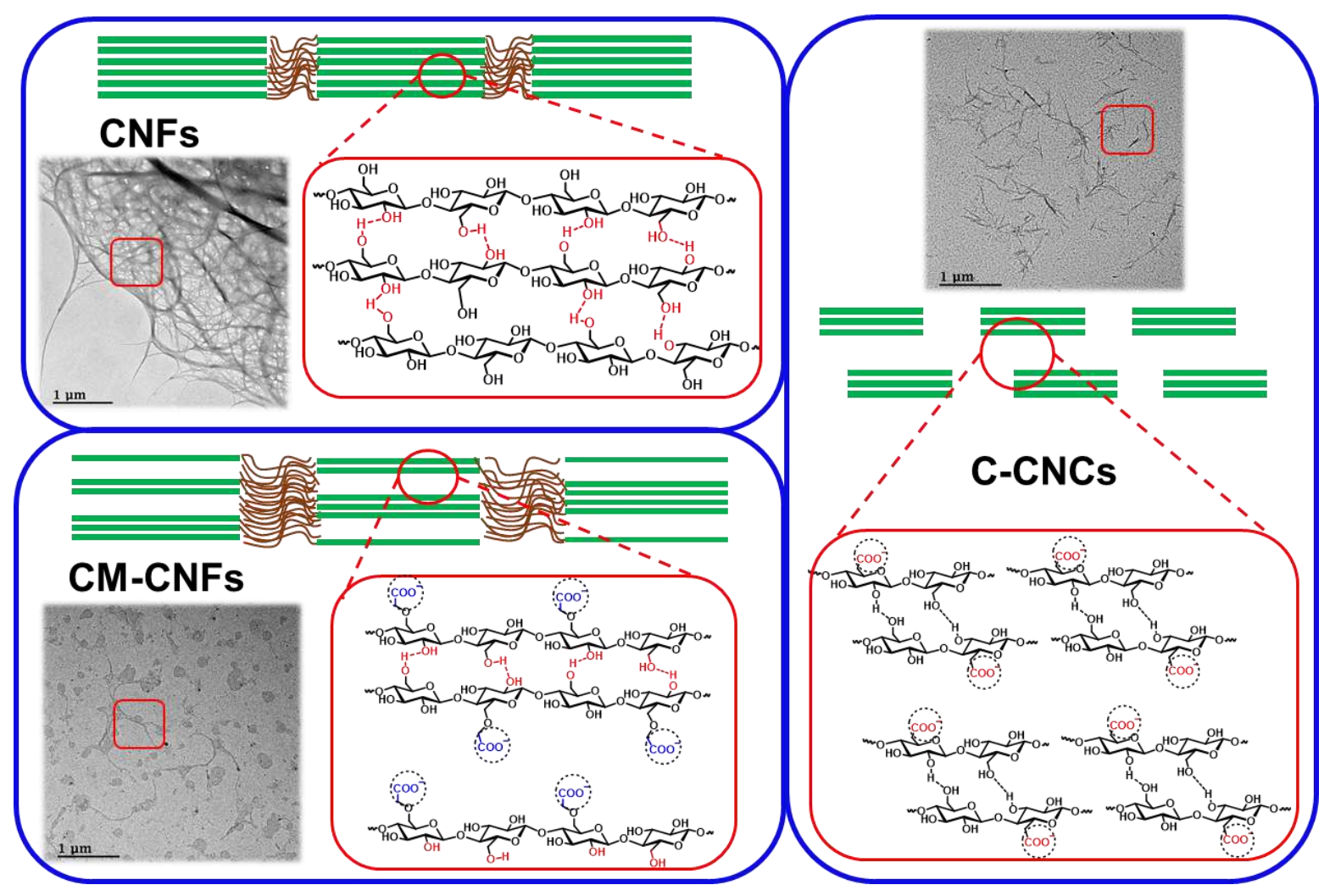

407 Scheme 3. Schematic of the structures of the different nanocellulose samples alongside their 408 actual morphologies shown in the respective TEM images.

\section{$410 \quad 3.2$ Morphologies of the UF resins and nanocellulose films}

411 Table 3 lists the different UF resins and nanocellulose films fabricated using a spin coating

412 method and their properties were measured. The results show that the $R_{q}$ values of the UF resin

413 films vary, depending on their molar ratio and addition of a hardener during their preparation. It

414 can be observed that the 1.6 UF resins have smoother surfaces than those of the 1.0 UF resins, 
415 regardless of level of hardener used in their preparation. It can be observed that the 1.0 UF resin 416 prepared using a hardener has the highest $R_{q}$ value; however, the 1.6 UF resin prepared using a

417 hardener has the lowest $R_{q}$ value. This is because the 1.0 UF resins features crystalline domains, 418 especially when cured with hardener, while the 1.6 UF resins are amorphous as has been 419 previously reported (Wibowo and Park 2021). The crystal domains of the 1.0 UF resins, which 420 are shown in the AFM image in Fig. 2b make the surface rough, resulting in the materials 421 exhibiting high $R_{q}$ values. Moreover, as shown in Figs. 2a and $\mathbf{b}$, the 1.0 UF resins have pores 422 distributed across their surfaces, which are not observed for the 1.6 UF resins shown in Figs. 2c 423 and $\mathbf{d}$. These pores are formed by the evaporation of water from the sample, which might 424 contribute to the roughness of the 1.0 UF resins. It seems that the evaporation might occur in an 425 uneven manner from the 1.0 UF resins, probably because of the uneven distribution of the 426 crystalline domains in the 1.0 UF resins. This is supported by the fact that the pores are primarily 427 formed around the crystalline domains, as shown in Fig. $\mathbf{2 b}$, which can be seen in the enlarged 428 image shown in Fig. S3 in the supplementary information. These results are in line with those of 429 another study in the literature, which reported that semicrystalline poly(ethylene terephthalate) 430 (PET) has a higher roughness than the amorphous PET polymer (Junkar et al. 2009). 431 Furthermore, the nanocellulose films have various thicknesses and $R_{q}$ values according to the 432 different nanocellulose types. As expected, the edge thickness is greater than the middle 433 thickness in all cases. This is attributed to the edge bead formation resulting from an increase in 434 the friction between the air and the substrate at the periphery, and a faster drying at the edge 435 during the rotation of the spin-coater (Atthi et al. 2009). Moreover, the obtained thickness and $R_{q}$ 436 values of the nanocellulose films are in the range of or similar to the results previously reported 437 in the literature (Yokota et al. 2007; Ahola et al. 2008). However, the results for the CNFs are 
worse than those of the $\mathrm{CM}-\mathrm{CNFs}$ and $\mathrm{C}-\mathrm{CNCs}$, indicating that the negative charges attributed

439 to the carboxymethyl $\left(\mathrm{CH}_{3} \mathrm{COO}^{-}\right)$or carboxylate $\left(\mathrm{COO}^{-}\right)$ions have a significant repulsion effect

440 during the manufacture of the film. These repulsive anion-anion electrostatic forces prevent their

441 molecular agglomeration that occurs because of the formation of strong hydrogen bonds when

442 the molecules are very close. It has been reported that highly charged nanocellulose has a dense

443 and smooth surface structure (Ahola et al. 2008). This makes it easier to liberate fibrils from the

444 structure, which results in smaller and more uniform dimensions. This is supported by the AFM

445 images of the nanocellulose films with a scan size of $50 \times 50 \mu \mathrm{m}$ (Fig. $\mathbf{S 4}$ in the supplementary

446 information). The structures of the $\mathrm{CM}-\mathrm{CNFs}$ and $\mathrm{C}-\mathrm{CNCs}$ films can be observed as being more

447 uniform and denser (less open) compared to that of the CNFs film. Moreover, the CNFs film has

448 a rougher surface with the presence of some big fibers, probably because of the aggregation or

449 web-like morphology of the CNFs. However, interestingly, the C-CNCs film is very uniform,

450 which is primarily related to the smaller size of the nanocellulose fibrils in this sample, as shown

451 in Scheme 3, compared to in the other samples.

452

453 Table 3. Film properties of different UF resins and nanocellulose samples.

\begin{tabular}{ccccc}
\hline Sample for film & $\begin{array}{c}\text { Concentration } \\
(\%)\end{array}$ & $\begin{array}{c}\text { Edge thickness } \\
(\mathrm{nm})\end{array}$ & $\begin{array}{c}\text { Middle thickness } \\
(\mathrm{nm})\end{array}$ & $\begin{array}{c}\text { Surface roughness, } \\
R_{q}(\mathrm{~nm})\end{array}$ \\
\hline \multirow{2}{*}{$1.0 \mathrm{UF}$ resins } & $+0 \% \mathrm{NH}_{4} \mathrm{Cl}$ & $*$ & & $2.32 \pm 1.03$ \\
& $+3 \% \mathrm{NH}_{4} \mathrm{Cl}$ & & & $4.48 \pm 0.70$ \\
& $+0 \% \mathrm{NH}_{4} \mathrm{Cl}$ & & $2.07 \pm 0.40$ \\
$1.6 \mathrm{UF}$ resins & $+3 \% \mathrm{NH}_{4} \mathrm{Cl}$ & & $0.58 \pm 0.21$ \\
\hline $\mathrm{CNFs}$ & 0.1 & $39.79 \pm 0.35$ & $34.54 \pm 1.17$ & $7.52 \pm 1.18$ \\
$\mathrm{CM}-\mathrm{CNFs}$ & 0.1 & $26.49 \pm 3.40$ & $9.75 \pm 1.58$ & $3.57 \pm 0.19$
\end{tabular}



C-CNCs
0.1
$24.64 \pm 0.20$
$7.19 \pm 0.53$
$2.68 \pm 0.38$

454

455

456

457

458

459

460 edge and middle) and has a higher $R_{q}$ value compared with the CM-CNFs and C-CNCs.

461 Moreover, abundant white spots and big fibers can be observed on the surface of the CNFs,

462 thought to have formed because of the aggregation of the CNFs via hydrogen bonds and van der

463 Waals forces, which might have occurred during their drying (Peng et al. 2012; Niu et al. 2018).

464 During the drying of the CNFs, the forces resulting from the removal of water at high

465 temperature may drive the molecular contact that facilitates the occurrence of the above forces

466 (Peng et al. 2012). The aggregation of the CNFs can be clearly observed in the enlarged AFM

467 image shown in Fig. 2h, which is very different from what is observed in the AFM images of the

468 CM-CNFs and C-CNCs shown in Fig. 2i-j. Similarly, the agglomeration of CNFs on the

469 smooth surface of PVA and Si wafer has been observed from AFM analysis (De Souza et al.

470 2017; Niu et al. 2018). Furthermore, the analysis of the coverage of the nanocellulose samples on

471 the Si surface was evaluated using XPS to verify the AFM results.

472

473
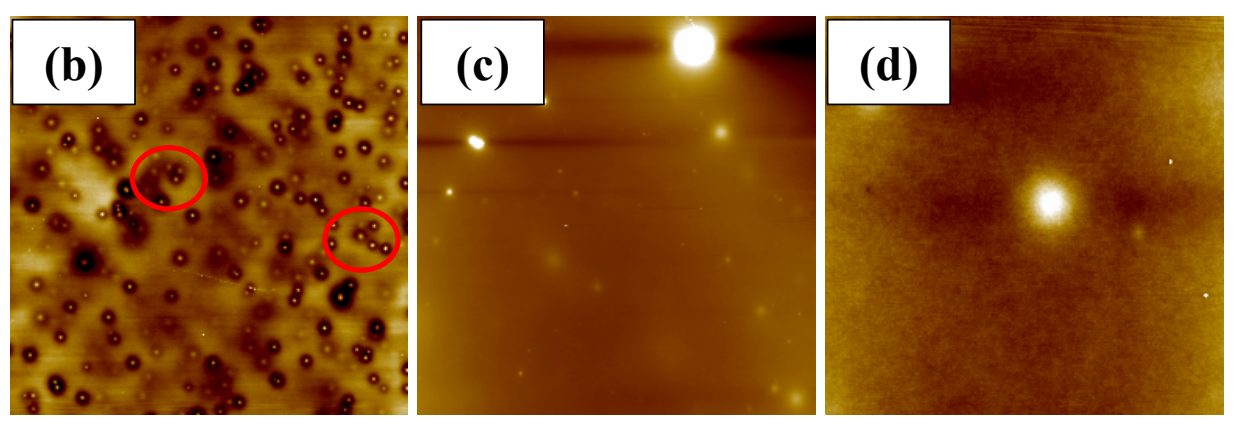

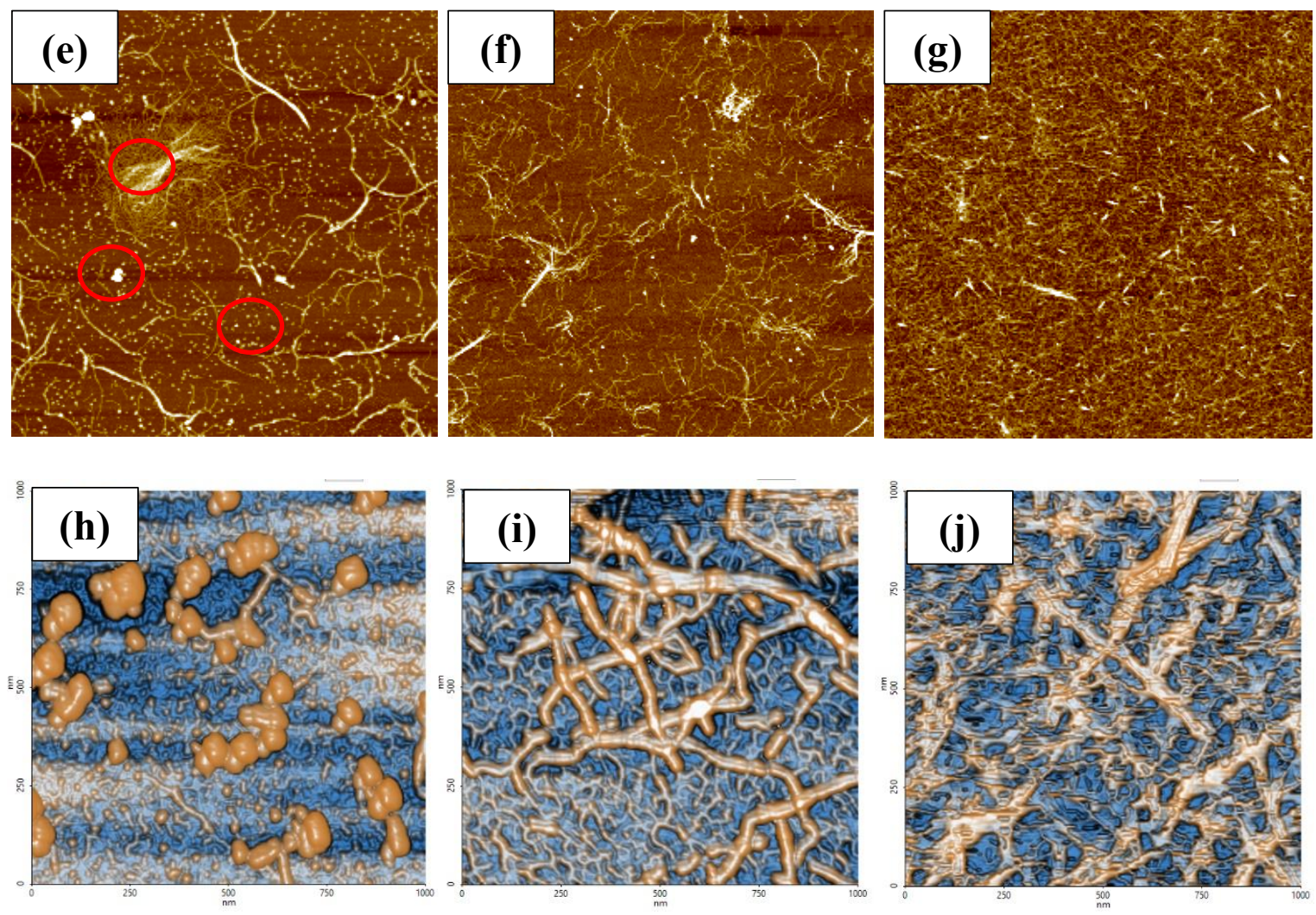

476 Fig. 2. AFM images $(50 \times 50 \mu \mathrm{m})$ of the films of the cured UF resins with the two molar ratios

477 and hardener contents. (a) 1.0 UF resin, (b) 1.0 UF resin + hardener, (c) 1.6 UF resin, and (d) 1.6

478 UF resin + hardener. AFM images $(10 \times 10 \mu \mathrm{m})$ of the different nanocellulose films: (e) CNFs,

479 (f) $\mathrm{CM}-\mathrm{CNFs}$, and (g) $\mathrm{C}-\mathrm{CNCs}$ and their color contrast AFM images $\left(1 \mu \mathrm{m}^{2}\right)$ : (h) CNFs, (i)

480 CM-CNFs, and (j) C-CNCs.

482 Low-resolution XPS (Fig. S5) was used to determine the chemical compositions of the

483 nanocellulose model films and a Si wafer pre-treated with PDADMAC was used as a reference.

484 In the XPS spectra, the highest intensity was generated by $\mathrm{O}_{1 \mathrm{~s}}$ followed by $\mathrm{C}_{1 \mathrm{~s}}$ and $\mathrm{Si}_{2 \mathrm{p}}$,

485 regardless of the nanocellulose type. However, for the reference film, the total intensity of $\mathrm{Si}_{2 p}$

486 was higher than that of $\mathrm{C}_{1 \mathrm{~s}}$, indicating that the surface of the $\mathrm{Si}$ wafer might not be well covered. 
Table $\mathbf{S 1}$ shows the quantitative chemical analysis related to the film coverage. The highest 488 percentage of Si was detected in the reference film, but it was significantly decreased after the 489 deposition of nanocellulose on the Si surface. As is consistent with the AFM analysis, the CM$490 \mathrm{CNFs}$ and $\mathrm{C}-\mathrm{CNCs}$ films contain a low $\mathrm{Si}$ content $(<5 \%)$, indicating good sample coverage 491 because of the uniform and compact distribution of the nanocellulose particles. However, the 492 CNFs film shows the opposite, with a relatively high Si content ( 10\%). Nevertheless, compared 493 with the percentage of $\mathrm{Si}$ in the reference $(\sim 30 \%)$, this value is good enough and still lower than 494 that reported in another study in the literature (Ahola et al. 2008). These results indicate that, in 495 general, the surface of all of the nanocellulose films show good coverage. Another notable 496 difference between the samples is in their carbon content. The percentage of carbon in the CNFs 497 is lower than that in the $\mathrm{CM}-\mathrm{CNF}$ and $\mathrm{C}-\mathrm{CNCs}$, primarily due to the CNFs having less film 498 coverage also because of the absence of additional functional groups such as carboxymethyl $499\left(\mathrm{CH}_{3} \mathrm{COO}^{-}\right)$or carboxylate $\left(\mathrm{COO}^{-}\right)$groups that contain carbon atoms. The presence of several 500 types of functional groups in the $\mathrm{CNFs}, \mathrm{CM}-\mathrm{CNFs}$, and $\mathrm{C}-\mathrm{CNCs}$ was confirmed from their 501 high-resolution $\mathrm{C}_{1 \mathrm{~s}}$ XPS spectra, shown in Fig. 3. These spectra display four typical peaks, 502 namely, $\mathrm{C} 1(\mathrm{C}-\mathrm{C}, \sim 284 \mathrm{eV}), \mathrm{C} 2(\mathrm{C}-\mathrm{O}, \sim 286 \mathrm{eV}), \mathrm{C} 3(\mathrm{O}-\mathrm{C}-\mathrm{O}$ or $\mathrm{C}=\mathrm{O}, \sim 287 \mathrm{eV})$, and $\mathrm{C} 4$ $503(\mathrm{C}-\mathrm{C}=\mathrm{O}, \sim 289 \mathrm{eV}$ ) (Niu et al. 2018). The $\mathrm{C} 1, \mathrm{C} 2$, and $\mathrm{C} 3$ peaks are detected in the spectra of all 504 of the nanocellulose films, while $\mathrm{C} 4$ is only observed in the spectra of the $\mathrm{CM}-\mathrm{CNFs}$ and $\mathrm{C}-$ 505 CNCs. This is because only these nanocellulose samples feature functional groups that contain $506 \mathrm{C}-\mathrm{C}=\mathrm{O}$. Moreover, only the $\mathrm{C} 1$ peak was detected in the spectrum of the reference film, 507 reflecting the $\mathrm{C}-\mathrm{C}$ bonds in the PDADMAC compound. 

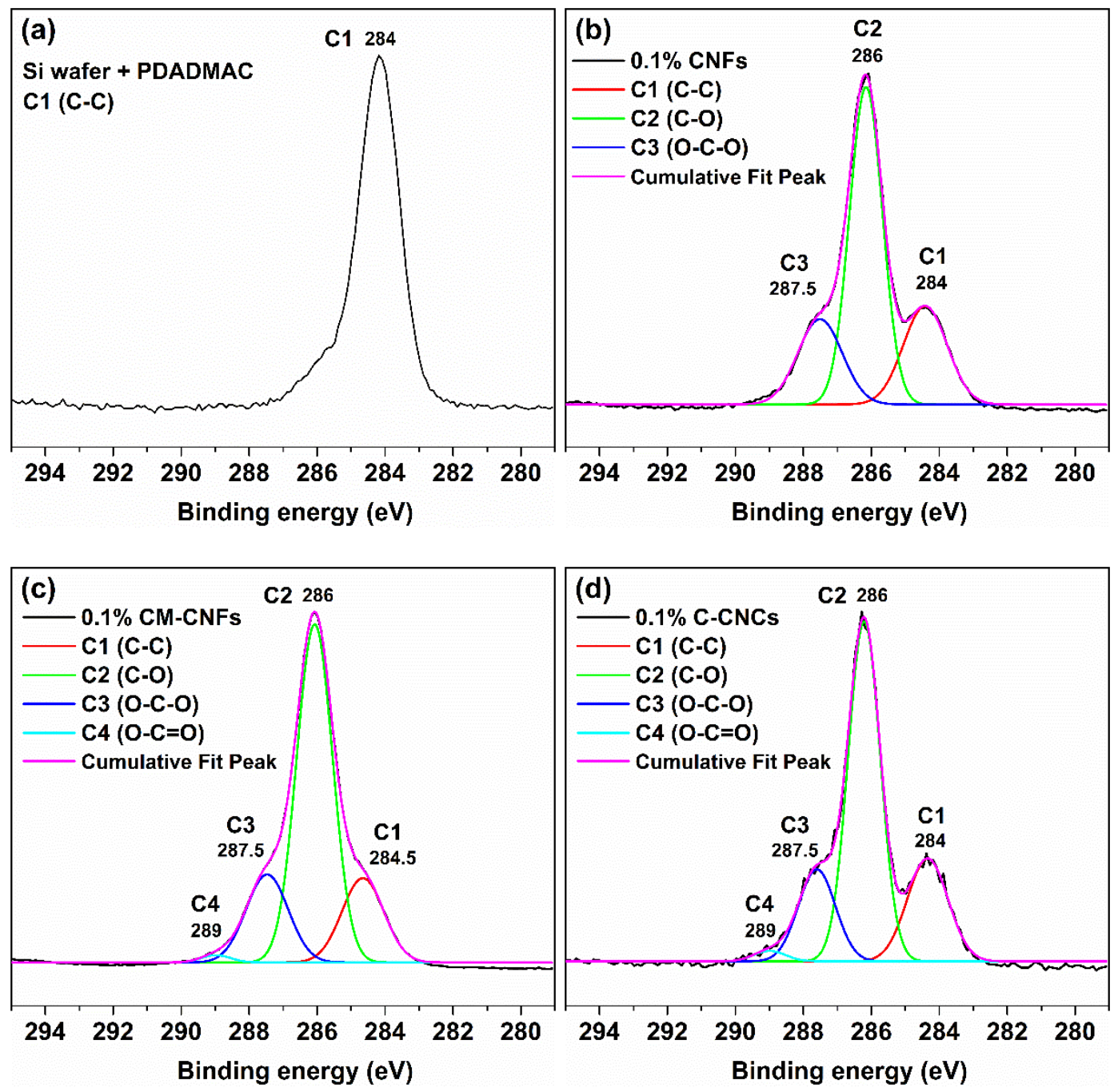

511 Fig. 3 Deconvolution of the high-resolution $\mathrm{C}_{1 \mathrm{~s}}$ XPS spectra of the reference and nanocellulose

512 films. (a) Si wafer + PDADMAC, (b) CNFs, (c) CM-CNFs, and (d) C-CNCs.

$514 \quad 3.3$ Adhesion force, wettability, and work of adhesion between the UF resins and

$515 \quad$ nanocellulose films

516 Fig. 4 shows the typical force-distance curves of the adhesion force measurements between a

517 droplet of the UF resins in the two molar ratios and the film surfaces of the nanocellulose 
518 samples. Fig. S6 shows the images taken at the maximum adhesion point of these curves. The

519 measurement is divided into four stages: 1) approaching the film surface toward the liquid

520 droplet until the surface of the film makes contact with the surface of the liquid droplet in an

521 equilibrium; 2) retracting the film downward, which changes the state from an advancing to a

522 receding one, and the adhesion force between the droplet and the film surface increases until

523 maximum and the $\theta_{\max }$ is reached; 3) stretching the film surface from the surface of the droplet

524 by keep moving the solid film down; and 4) final detachment of the surface of the film sample

525 from the surface of the droplet. The force value at the peak of the curve is referred as the

526 maximum adhesion force $\left(F_{\max }\right)$, which represents the surface adhesion between a liquid droplet

527 and a solid film surface (Sun et al. 2017). Table S2 shows a summary of the experimental data of

528 the adhesion force measurements. As expected, the 1.6 UF resins exhibit a higher adhesion force

529 with the nanocellulose surface than the 1.0 UF resins, regardless of the nanocellulose type, as

530 shown in the data in Table 4. According to the properties of the resins, as shown in Table 2, the

531 1.6 UF resins are more reactive, showing a shorter gelation time, and have a greater viscosity and

$532 \mathrm{M}_{\mathrm{w}}$ than the 1.0 UF resins. It is believed that these differences result in the stronger adhesion

533 force of the 1.6 UF resins than the 1.0 UF resins with the surfaces of the nanocellulose samples.

534 The adhesion forces between the UF resins and nanocellulose may be related to dispersion and

535 dipole-dipole (hydrogen bonds) molecular interactions. A large molecular size is known to be a

536 factor in the strong dispersion forces between molecules. Compared to smaller molecules, large

537 molecules are more easily polarized. In other words, easier distribution of electrons around large

538 molecules facilitates the formation of temporary dipoles, resulting in stronger molecular

539 interactions. Furthermore, as shown in Table 4, among nanocellulose samples, CNFs exhibit the

540 lowest $F_{\max }$ values with the two UF resins, while the other nanocellulose samples show similar 
541 values. The reason for this can be attributed to the fact that both the CM-CNFs and C-CNCs

542 have additional negative charges compared to the CNFs, which contribute toward the dipole-

543 dipole forces between their molecules and the UF resins. Moreover, the aggregation and rough

544 surface of the CNFs film may contribute to the lower adhesion force. However, the difference

545 the $F_{\max }$ values of the samples is not great, therefore, it can be concluded that the adhesion forces

546 between the UF resins with F/U ratios of 1.0 or 1.6 and the three types of nanocelluloses are

547 relatively similar.

548

549
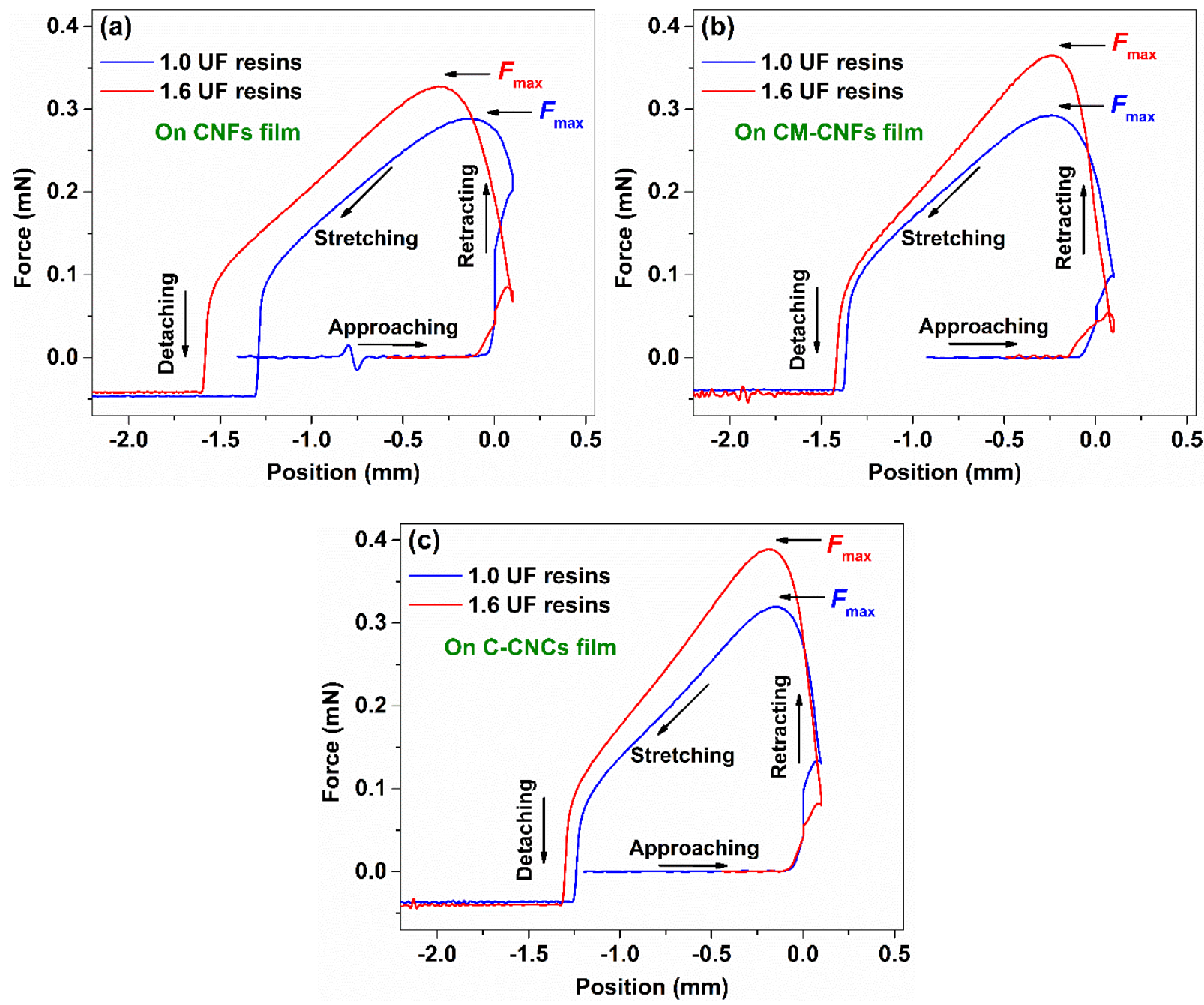
551 Fig. 4. Typical force-distance curves recorded for the different molar ratios of UF resin droplets

552 on the surfaces of the nanocellulose model films. (a) CNFs, (b) CM-CNFs, and (c) C-CNCs.

554 Table 4. Maximum adhesion force between two molar ratio UF resins and different 555 nanocellulose films

\begin{tabular}{ccc}
\hline \multirow{2}{*}{ Nanocellulose film type } & \multicolumn{2}{c}{$F_{\max } / \mathrm{area}\left(\mathrm{mN} / \mathrm{mm}^{2}\right)$} \\
\cline { 2 - 3 } & 1.0 UF resins & 1.6 UF resins \\
\hline CNFs & $0.049 *$ & 0.055 \\
CM-CNFs & 0.053 & 0.059 \\
C-CNCs & 0.053 & 0.060
\end{tabular}

*All standard deviations are $\leq 0.001$, except for the CNFs vs 1.0 UF resins which is 0.0024 (see Table S2)

559 There are several factors that affect the surface wettability of a polymer, such as its molecular

560 structure, $\mathrm{M}_{\mathrm{w}}$, PDI, surface topography, and surface roughness (Hirai et al. 2014). In this study,

561 the effects of such factors on the wettability and surface energy were investigated. Fig. 5 shows

562 the contact angles of water and diiodomethane on the surfaces of the different UF resin films. It

563 is clear from these images that there is a remarkable difference in the contact angles of water and

564 diiodomethane. Thermosetting polymers such as cured UF resins, which are supposed to be

565 hydrophobic (Yilgor et al. 2012), are more preferably wetted with diiodomethane rather than

566 water. This is because diiodomethane is non-polar owing to its molecular symmetry, while water

567 is a strong polar liquid. Although there is a slight difference in the magnitude of the contact angle

568 between the UF resin films with different molar ratios and hardener levels, the 1.6 UF resins are

569 more hydrophobic than the 1.0 UF resins, regardless of the level of hardener, as shown in Fig. 5.

570 There are several reasons behind this behavior. The first reason is that the 1.6 UF resins have

571 higher $\mathrm{M}_{\mathrm{w}}$ values than the 1.0 UF resins. The second is that the $1.6 \mathrm{UF}$ resins contain more 
572 branched molecules and exhibit highly cross-linked structures when they are cured (Wibowo and

573 Park 2021). As expected, the greater the number of molecules in thermosetting resins, the higher

574 their water resistance. This is attributed to the high proportion of covalent bonds (methylene and

575 methyl ether linkages) that form in the chemical structure. The third reason is that the $1.6 \mathrm{UF}$

576 resins are amorphous with low $R_{q}$ values, while the 1.0 UF resins are semicrystalline with high

$577 R_{q}$ values. In general, the smoother the surface of a polymer, the lower its water contact angle,

578 which has been already discussed in some studies in the literature (Bikernian 1950; Wang et al.

579 2020b). In this case, the opposite is true, as the surface roughness of the 1.6 UF resins is lower

580 than that of the 1.0 UF resins. As mentioned above, there are various factors that affect the

581 wettability of a polymer surface. Thus, the dominant factors are possibly the chemical structure

582 and molecular weight in the case of the UF resins. Furthermore, these results are consistent with

583 another published study in the literature, which investigated the water contact angles of

584 thermosetting polyurethane films (Brzeska et al. 2017). They demonstrated that semicrystalline

585 linear polyurethane has a lower contact angle than amorphous cross-linked polyurethane that has

586 a smoother surface. In addition to the other contributing factors mentioned earlier, another

587 possible cause of this phenomenon is the micro- or nano-size pores present in the materials,

588 which has been explained in another report (Łojkowski et al. 2019). It appears that the numerous

589 pores in the 1.0 UF resin films (Figs. 2a and b) contribute to these materials having low water

590 contact angles. Furthermore, in the case of the addition of hardener, it seems that it makes the

591 resins slightly more hydrophobic. This is because the hardener facilitates the condensation

592 reaction, resulting in the formation of a long polymer that has abundant covalent bonding,

593 thereby leading to a high contact angle with water and a lower contact angle with diiodomethane. 

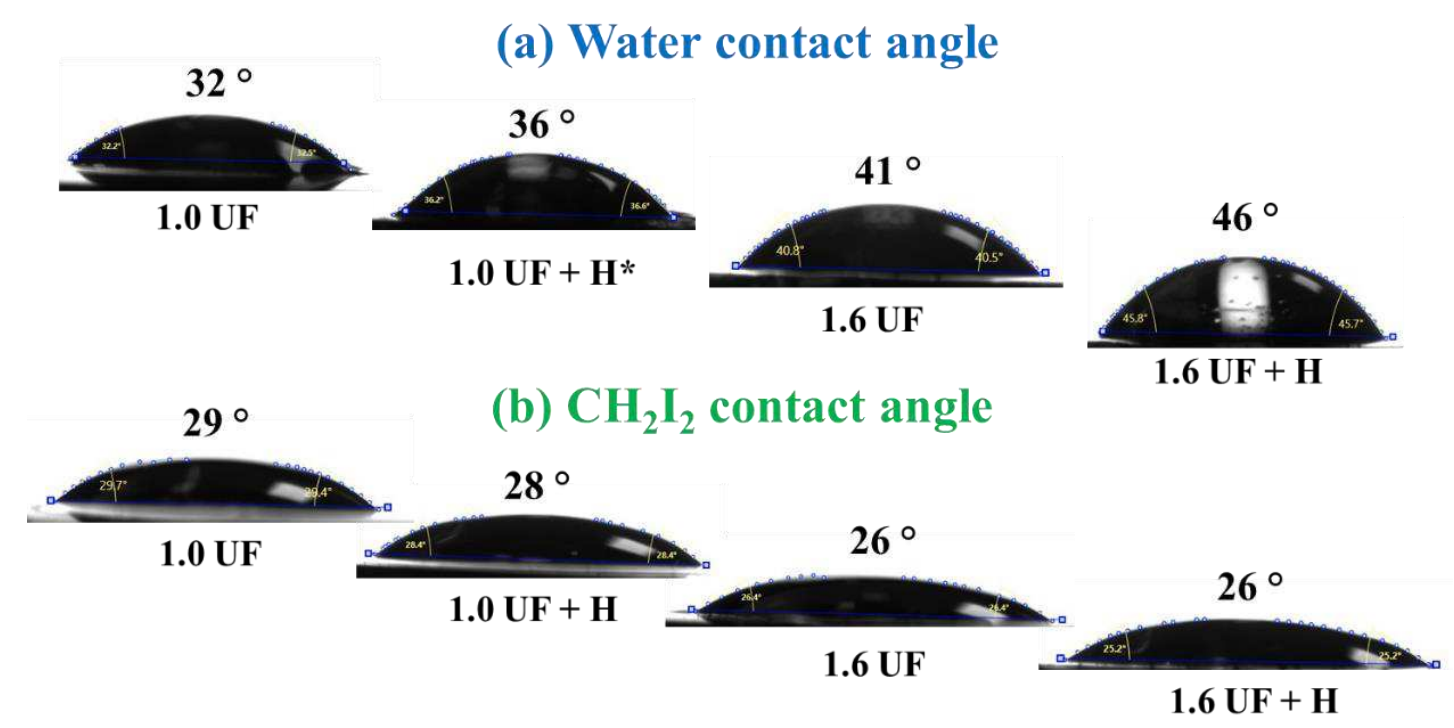

595 Fig. 5. Example of water and diiodomethane contact angle measurements on different UF resins 596 films. ${ }^{*} \mathrm{H}$ indicates that $3 \% \mathrm{NH}_{4} \mathrm{Cl}$ was used as a hardener.

598 The surface energy $(\gamma)$, which is defined as the energy change divided by the change in the 599 surface area, has become one of the fundamental parameters in polymer science (Gong et al. 600 2019). Various methods have been employed to estimate the surface energy of a polymer 601 substrate, of which one of the most widely used methods is the measurement of contact angles 602 for the OCG method (van Oss et al. 1988). The surface energies of the UF resins and 603 nanocellulose films were calculated based on the contact angles of three different liquids on their 604 surfaces, which are presented in Table S3. Table 5 summarizes the results of the surface energy 605 components obtained using the OCG method. From the data, it appears that the total surface 606 energies $\left(\gamma^{T o t}\right)$ of the UF resins and nanocellulose films are relatively similar, but the 1.6 UF 607 resins have higher $\gamma^{T o t}$ values than the 1.0 UF resins. It is clear for the results that $\gamma^{L W}$ makes a 608 more dominant contribution to the value of $\gamma^{T o t}$ than $\gamma^{A B}$. As shown in Table 5, the value of $\gamma^{L W}$ is 609 much higher than $\gamma^{A B}$, primarily because of the large molecules and high amount of covalent 
610 bonding in the cured UF resins and nanocellulose polymers. This shows that $\gamma^{L W}$ increases as the

611 molar ratio increases from 1.0 to 1.6 , indicating that the 1.6 UF resins contain bigger polymers

612 than the 1.0 UF resins. The dispersion interaction $\left(\gamma^{L W}\right)$ depends on the polarizability of a

613 molecule. The larger the polymer, the more polarized it is. Thus, the 1.6 UF resins that have

614 higher $\mathrm{M}_{\mathrm{w}}$ values have greater $\gamma^{L W}$ values, which are consistent with the adhesion force

615 measurements. It was found in another study that a high concentration of methylene linkages

$616\left(-\mathrm{CH}_{2}-\right)$ in paraffin wax and a decrease in its crystallinity resulted in higher surface energy $(\mathrm{Pu}$

617 and Severtson 2009), which is in line with the results in this work. However, the polar

618 contribution denoted as $\gamma^{A B}$ is higher in the 1.0 UF resins, which could be attributed to the

619 materials mainly being composed of linear molecules that easily form hydrogen bonds (Wibowo

620 et al. 2020b), either between the linear molecules or between the UF resin molecules and the

621 water used for the contact angle measurements. Hydrogen bonding is considered to be a dipole-

622 dipole force and makes a contribution to the polar interaction. Another notable difference can be

623 observed in the individual acid $\left(\gamma^{+}\right)$and base $\left(\gamma^{-}\right)$surface energies, where $\gamma^{-}$is significantly

624 higher than $\gamma^{+}$, regardless of the molar ratios of the UF resins. The reason for this is that the UF

625 resins consist of an abundance of electron donating groups, such as $-\mathrm{C}=\mathrm{O},-\mathrm{OH}$, and $-\mathrm{NH}$. Thus,

626 it can be concluded that even though the $\gamma^{T o t}$ values of the UF resins are very similar, there are

627 notable differences in their dispersive and polar surface energies because of their different

628 chemical properties. Similarly, this phenomenon is observed for the nanocellulose materials. The

$629 \gamma^{-}$values are significantly higher than the $\gamma^{+}$values, indicating the presence of an abundance of

630 electron donating groups in the nanocellulose structure. Interestingly, the $\gamma^{-}$values of the $\mathrm{CM}_{-}$

631 CNFs and $\mathrm{C}-\mathrm{CNCs}$ are higher than that of the CNFs, possibly due to the presence of anionic 632 groups such as carboxymethyl $\left(\mathrm{CH}_{3} \mathrm{COO}^{-}\right)$or carboxylate $\left(\mathrm{COO}^{-}\right)$. 
634 Table 5. The surface energies $\left(\mathrm{mJ} \mathrm{m}^{-2}\right)$ calculated using the contact angle measurements of the 635 materials, via the OCG method.

\begin{tabular}{cccccc}
\hline Film & $\gamma^{L W}$ & $\gamma^{+}$ & $\gamma^{-}$ & $\gamma^{A B}$ & $\gamma^{T o t}$ \\
\hline 1.0 UF resins & 44.76 & $6.8 \times 10^{-4}$ & 57.68 & 0.37 & 45.13 \\
1.0 UF resin $+\mathrm{H}^{*}$ & 44.92 & $3.2 \times 10^{-4}$ & 45.36 & 0.24 & 45.16 \\
1.6 UF resin & 45.45 & $6.7 \times 10^{-4}$ & 42.56 & 0.34 & 45.79 \\
1.6 UF resin $+\mathrm{H}$ & 45.79 & $2.2 \times 10^{-7}$ & 35.24 & 0.01 & 45.80 \\
CNFs & 38.30 & $4.3 \times 10^{-2}$ & 55.45 & 3.08 & 41.38 \\
CM-CNFs & 40.82 & $2.7 \times 10^{-3}$ & 57.68 & 0.79 & 41.61 \\
C-CNCs & 41.17 & $3.6 \times 10^{-2}$ & 55.46 & 2.83 & 44.00 \\
\hline
\end{tabular}

*H indicates that $3 \% \mathrm{NH}_{4} \mathrm{Cl}$ was added as a hardener.

638 Furthermore, the work of adhesion $\left(W_{12}\right)$ values of the UF resins and nanocellulose films

639 calculated from the surface energies using Eq 5 are presented in Table 6. Consistent with the

640 adhesion force results, the $W_{12}$ values between the 1.6 UF resins and nanocellulose are higher

641 than for the 1.0 UF resins, regardless of the nanocellulose type. As explained earlier, the greater

$642 \mathrm{M}_{\mathrm{w}}$ values of the 1.6 UF resins are related to the high $\gamma^{L W}$ values and lead to higher $\gamma^{T o t}$ and $W_{12}$ 643 values. This suggests that dispersion forces are dominant in the adhesion between the 644 thermosetting UF resins and nanocellulose, which is in agreement with the results of another 645 study (Gustafsson et al. 2012), which showed that van der Waals interactions play a dominant 646 role in the adhesive interactions between lignin, cellulose, and hemicellulose. Furthermore, the 647 smoother surfaces of the 1.6 UF resin films compared with those of the 1.0 UF resins may 648 contribute to the higher $W_{12}$ values. In summary, it can be concluded that the molecular 
649 interactions between the 1.6 UF resins and different nanocellulose model surfaces are stronger

650 than for the 1.0 UF resins as the 1.6 UF resins have more branched structures, smoother surfaces,

651 and higher surface energies. In addition, the chemical structure, negative charge, and surface

652 topography of nanocellulose materials also contribute to their adhesion with UF resins.

653

654 Table 6. Work of adhesion $\left(W_{12}, \mathrm{~mJ} / \mathrm{m}^{2}\right)$ values between the different nanocellulose types and 655 UF resin films.

\begin{tabular}{ccccc}
\hline Nanocellulose & \multicolumn{4}{c}{ UF resin adhesives } \\
\cline { 2 - 5 } types & 1.0 UF resin & 1.6 UF resin & 1.0 UF resin $+\mathrm{H}^{*}$ & 1.6 UF resin $+\mathrm{H}$ \\
\hline CNFs & 86.12 & 86.53 & 86.01 & 86.22 \\
CM-CNFs & 86.62 & 87.22 & 86.61 & 87.09 \\
C-CNCs & 88.93 & 89.38 & 88.83 & 89.11 \\
\hline
\end{tabular}

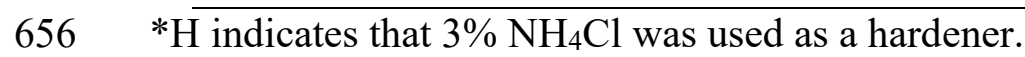

\section{4. Conclusion}

658 In the present work, the adhesion between different nanocellulose materials and UF resin 659 adhesives was directly measured. The adhesion forces between the nanocellulose films (CNFs, $660 \mathrm{CM}-\mathrm{CNFs}$, and $\mathrm{C}-\mathrm{CNCs})$ and liquid droplets of the UF resins $(1.0$ and $1.6 \mathrm{~F} / \mathrm{U})$, and the work of 661 adhesion values between films of the nanocellulose materials and UF resins using contact angle 662 measurements and calculated via the van Oss-Chaudhury-Good method were determined. The 663 results show that the interactions between the 1.6 UF resins and nanocellulose materials are 664 stronger than those of the 1.0 UF resins, which is proven from its greater adhesion force and 665 work of adhesion values with the different types of nanocellulose materials. This is attributed to 
666 the 1.6 UF resins having a more branched structure (high $\mathrm{M}_{\mathrm{w}}$ ), being more reactive (short 667 gelation time), with a smoother surface, and higher surface energy than their 1.0 UF resin

668 counterparts. These properties contribute to the high value of dispersive surface energy $\left(\gamma^{L W}\right)$, 669 suggesting that van der Waals forces are mainly responsible for the adhesion interaction. Overall, 670 the results of this study provide a new insight on understanding the interaction between the most

671 widely used thermosetting wood adhesive, UF resins, and nanocellulose as the most major 672 component in the wood cell wall. However, knowledge of the adhesion interaction of wood 673 adhesive with other wood biopolymers such as lignin and hemicellulose are necessary to better 674 understand the nature of the adhesion of wood when these biopolymers interact with the 675 adhesive.

\section{Supplementary Information}

678 AFM images used in the measuring of the thickness of the samples (Fig. S1), TEM images of the 679 different cellulose samples (Fig. S2), AFM images of the 1.0 UF resin $+3 \% \mathrm{NH}_{4} \mathrm{Cl}(10 \times 10 \mu \mathrm{m})$ 680 and the different cellulose films (Fig. S3 and Fig. S4), the low-resolution XPS spectra (Fig. S5) 681 and their relative atomic concentrations of the cellulose films (Table S1), images of the adhesion 682 force measurements taken at the maximum adhesion point (Fig. S6) with the experimental data 683 of the adhesion force measurements (Table S2), and all of the contact angle values from the 684 three different liquids (Table S3) related to this article are presented in the supporting 685 information.

\section{Author Contributions}

688 All authors contributed equally to this manuscript. 


\section{Acknowledgments}

690 This work was supported by the National Research Foundation (NRF) of Korea funded by the 691 Korean Government (MSIT) (Grant No. 2020R1A2C1005042).

692

693 Compliance with ethical standards

694 Conflict of interest The authors declare no competing financial interest.

695 Ethical approval All applicable international, national, and/ or institutional guidelines for the 696 care and use of animals were followed.

697

\section{REFERENCES}

Ahola S, Salmi J, Johansson LS, et al (2008) Model films from native cellulose nanofibrils. Preparation, swelling, and surface interactions. Biomacromolecules 9:1273-1282. https://doi.org/10.1021/bm701317k

Atthi N, Nimittrakoolchai OU, Jeamsaksiri W, et al (2009) Study of optimization condition for spin coating of the photoresist film on rectangular substrate by Taguchi design of an experiment. Songklanakarin J Sci Technol 31:331-335

Bhandari PN, Jones DD, Hanna MA (2012) Carboxymethylation of cellulose using reactive extrusion. Carbohydr Polym 87:2246-2254. https://doi.org/10.1016/j.carbpol.2011.10.056

707 Bikernian JJ (1950) Surface Roughness and Contact Angle. J Phys Colloid Chem 54:653-658. 708 https://doi.org/10.1021/j150479a008

709 Brzeska J, Morawska M, Heimowska A, et al (2017) The influence of chemical structure on thermal 710 properties and surface morphology of polyurethane materials. Chem Pap 72:1249-1256. 711 https://doi.org/10.1007/s1 1696-017-0358-6 
712 Carrick C, Pendergraph SA, Wågberg L (2014) Nanometer smooth, macroscopic spherical cellulose

713 probes for contact adhesion measurements. ACS Appl Mater Interfaces 6:20928-20935. 714 https://doi.org/10.1021/am505673u

715 Cwikel D, Zhao Q, Liu C, et al (2010) Comparing contact angle measurements and surface tension 716 assessments of solid surfaces. Langmuir 26:15289-15294. https://doi.org/10.1021/la1020252

717 De Souza AG, Kano FS, Bonvent JJ, Dos Santos Rosa D (2017) Cellulose nanostructures obtained from 718 waste paper industry: A comparison of acid and mechanical isolation methods. Mater Res 20:209719 214. https://doi.org/10.1590/1980-5373-mr-2016-0863

720 Doh SJ, Lee JY, Lim DY, Im JN (2013) Manufacturing and analyses of wet-laid nonwoven consisting of 721 carboxymethyl cellulose fibers. Fibers Polym 14:2176-2184. https://doi.org/10.1007/s12221-013$722 \quad 2176-y$

723 Dos Santos DM, De Lacerda Bukzem A, Ascheri DPR, et al (2015) Microwave-assisted 724 carboxymethylation of cellulose extracted from brewer's spent grain. Carbohydr Polym 131:125725 133. https://doi.org/10.1016/j.carbpol.2015.05.051

726 Dunky M (1998) Urea-formaldehyde (UF) adhesive resins for wood. Int J Adhes Adhes 18:95-107

727 Eriksson M, Notley SM, Wågberg L (2007) Cellulose thin films: Degree of cellulose ordering and its 728 influence on adhesion. Biomacromolecules 8:912-919. https://doi.org/10.1021/bm061164w

729 Esmaeili N, Zohuriaan-Mehr MJ, Mohajeri S, et al (2017) Hydroxymethyl furfural-modified urea730 formaldehyde resin: synthesis and properties. Eur J Wood Wood Prod 75:71-80. $731 \quad$ https://doi.org/10.1007/s00107-016-1072-8

732 French AD (2020) Increment in evolution of cellulose crystallinity analysis. Cellulose 27:5445-5448. $733 \quad$ https://doi.org/10.1007/s10570-020-03172-z

734 Gibson LJ (2012) The hierarchical structure and mechanics of plant materials. J R Soc Interface 9:2749735 2766. https://doi.org/10.1098/rsif.2012.0341 
Gong L, Xiang L, Zhang J, et al (2019) Fundamentals and Advances in the Adhesion of Polymer Surfaces and Thin Films. Langmuir 35:15914-15936. https://doi.org/10.1021/acs.langmuir.9b02123

Gustafsson E, Johansson E, Wågberg L, Pettersson T (2012) Direct adhesive measurements between wood biopolymer model surfaces.

Biomacromolecules $13: 3046-3053$.

He X, Lu W, Sun C, et al (2020) Cellulose and cellulose derivatives: Different colloidal states and foodrelated applications. Carbohydr Polym 255:117334. https://doi.org/10.1016/j.carbpol.2020.117334

Hirai T, Osumi S, Ogawa H, et al (2014) Precise synthesis and surface wettability of a polymer with liquid crystalline side chains. Macromolecules 47:4901-4907. https://doi.org/10.1021/ma5010265

Hoeger IC, Filpponen I, Martin-Sampedro R, et al (2012) Bicomponent lignocellulose thin films to study the role of surface lignin in cellulolytic reactions. Biomacromolecules 13:3228-3240.

Hollertz R, Arwin H, Faure B, et al (2013) Dielectric properties of lignin and glucomannan as determined https://doi.org/10.1021/bm301001q

Jafarzadeh S, Thormann E, Rönnevall T, et al (2011) Toward homogeneous nanostructured by spectroscopic ellipsometry and Lifshitz estimates of non-retarded Hamaker constants. Cellulose 20:1639-1648. https://doi.org/10.1007/s10570-013-9980-9

754 Junkar I, Cvelbar U, Vesel A, et al (2009) The Role of Crystallinity on Polymer Interaction with Oxygen 755 Plasma. Plasma Process Polym 6:667-675. https://doi.org/10.1002/ppap.200900034

756 Karabulut E, Pettersson T, Ankerfors M, Wågberg L (2012) Adhesive layer-by-layer films of 757 carboxymethylated cellulose nanofibril-dopamine covalent bioconjugates inspired by marine mussel threads. ACS Nano 6:4731-4739. https://doi.org/10.1021/nn204620j

759 Khanjanzadeh H, Park BD (2021) Optimum oxidation for direct and efficient extraction of carboxylated 
cellulose nanocrystals from recycled MDF fibers by ammonium persulfate. Carbohydr Polym 251:117029. https://doi.org/10.1016/j.carbpol.2020.117029

762 Kondo T, Kose R, Naito H, Kasai W (2014) Aqueous counter collision using paired water jets as a novel 763 means of preparing bio-nanofibers. Carbohydr Polym 112:284-290. 764 https://doi.org/10.1016/j.carbpol.2014.05.064

765 Kontturi E, Johansson LS, Kontturi KS, et al (2007) Cellulose nanocrystal submonolayers by spin 766 coating. Langmuir 23:9674-9680. https://doi.org/10.1021/la701262x

767 Kontturi E, Suchy M, Penttilä P, et al (2011) Amorphous characteristics of an ultrathin cellulose film. 768 Biomacromolecules 12:770-777. https://doi.org/10.1021/bm101382q

769 Lai Y, Zhang H, Sugano Y, et al (2019) Correlation of Surface Morphology and Interfacial Adhesive 770 Behavior between Cellulose Surfaces: Quantitative Measurements in Peak-Force Mode with the 771 Colloidal Probe Technique. Langmuir 35:7312-7321. https://doi.org/10.1021/acs.langmuir.8b03503

772 Lefebvre J, Gray DG (2005) AFM of adsorbed polyelectrolytes on cellulose I surfaces spin-coated on 773 silicon wafers. Cellulose 12:127-134. https://doi.org/10.1007/s10570-004-1574-0

774 Leng W, Pan B (2019) Thermal insulating and mechanical properties of cellulose nanofibrils modified 775 polyurethane foam composite as structural insulated material. Forests 10:. 776 https://doi.org/10.3390/f10020200

777 Levendis D, Pizzi1 A, Ferg E (1992) The Correlation of Strength and Formaldehyde Emission with the 778 Crystalline/Amorphous Structure of UF Resins. Holzforschung 46:263-269. 779 https://doi.org/10.1515/hfsg.1992.46.3.263

780 Ling Z, Wang T, Makarem M, et al (2019) Effects of ball milling on the structure of cotton cellulose. $781 \quad$ Cellulose 26:305-328. https://doi.org/10.1007/s10570-018-02230-x

782 Łojkowski M, Walheim S, Jokubauskas P, et al (2019) Tuning the Wettability of a Thin Polymer Film by 783 Gradually Changing the Geometry of Nanoscale Pore Edges. Langmuir 35:5987-5996. 
785 Lubis MAR, Park BD, Lee SM (2017) Modification of urea-formaldehyde resin adhesives with blocked isocyanates using sodium bisulfite. Int $\mathrm{J}$ Adhes Adhes 73:118-124. https://doi.org/10.1016/j.ijadhadh.2016.12.001

Mahrdt E, Pinkl S, Schmidberger C, et al (2016) Effect of addition of microfibrillated cellulose to ureaformaldehyde on selected adhesive characteristics and distribution in particle board. Cellulose 23:571-580. https://doi.org/10.1007/s10570-015-0818-5

791 Melilli G, Carmagnola I, Tonda-Turo C, et al (2020) DLP 3D printing meets lignocellulosic biopolymers:

792 Carboxymethyl cellulose inks for 3D biocompatible hydrogels. Polymers (Basel) 12:1-11. 793 https://doi.org/10.3390/POLYM12081655

794 Nindiyasari F, Griesshaber E, Zimmermann T, et al (2016) Characterization and mechanical properties investigation of the cellulose/gypsum composite. J Compos Mater 50:657-672.

Niu X, Liu Y, Fang G, et al (2018) Highly Transparent, Strong, and Flexible Films with Modified Cellulose Nanofiber Bearing UV Shielding Property. Biomacromolecules 19:4565-4575.

Notley SM, Norgren M (2010) Surface energy and wettability of spin-coated thin films of lignin isolated from wood. Langmuir 26:5484-5490. https://doi.org/10.1021/la1003337

Park B-D, Jeong H-W (2011) Hydrolytic stability and crystallinity of cured urea-formaldehyde resin adhesives with different formaldehyde/urea mole ratios. Int $\mathrm{J}$ Adhes Adhes 31:524-529. https://doi.org/10.1016/j.ijadhadh.2011.05.001

Park BD, Frihart CR, Yu Y, Singh AP (2013) Hardness evaluation of cured urea-formaldehyde resins with different formaldehyde/urea mole ratios using nanoindentation method. Eur Polym J 49:3089_3094. https://doi.org/10.1016/j.eurpolymj.2013.06.013 
808

809

810

811

812

813

814

815

816

817

818

819

820

821

822

823

824

825

826

827

828

829

830

831

Peng Y, Gardner DJ, Han Y (2012) Drying cellulose nanofibrils: In search of a suitable method. Cellulose 19:91-102. https://doi.org/10.1007/s10570-011-9630-z

Pereira Oliveira Moreira RL, Simão JA, Gouveia RF, Strauss M (2020) Exploring the Hierarchical Structure and Alignment of Wood Cellulose Fibers for Bioinspired Anisotropic Polymeric Composites. ACS Appl Bio Mater 3:2193-2200. https://doi.org/10.1021/acsabm.0c00038

Pizzi A, Valenzuela J (1994) Theory and practice of the preparation of low formaldehyde emission uf adhesives. Holzforschung 48:254-261. https://doi.org/10.1515/hfsg.1994.48.3.254

Pu G, Severtson SJ (2009) Dependency of contact angle hysteresis on crystallinity for n-alkane substrates. J Phys Chem C 113:6673-6680. https://doi.org/10.1021/jp809988k

Qi ZD, Saito T, Fan Y, Isogai A (2012) Multifunctional coating films by layer-by-layer deposition of $\begin{array}{llll}\text { cellulose } \quad \text { and } \quad \text { chitin } \quad \text { nanofibrils. } & \text { Biomacromolecules }\end{array}$ https://doi.org/10.1021/bm201659b

Rundlöf M, Karlsson M, Wågberg L, et al (2000) Application of the JKR method to the measurement of adhesion to Langmuir-Blodgett cellulose surfaces. J Colloid Interface Sci 230:441-447. https://doi.org/10.1006/jcis.2000.7108

Sacui IA, Nieuwendaal RC, Burnett DJ, et al (2014) Comparison of the properties of cellulose nanocrystals and cellulose nanofibrils isolated from bacteria, tunicate, and wood processed using acid, enzymatic, mechanical, and oxidative methods. ACS Appl Mater Interfaces 6:6127-6138. https://doi.org/10.1021/am500359f

Sczech R, Riegler H (2006) Molecularly smooth cellulose surfaces for adhesion studies. J Colloid Interface Sci 301:376-385. https://doi.org/10.1016/j.jcis.2006.05.021

Stelte W, Sanadi AR (2009) Preparation and characterization of cellulose nanofibers from two commercial hardwood and softwood pulps. Ind Eng Chem Res 48:11211-11219. https://doi.org/10.1021/ie9011672 
832 Sun Y, Jiang Y, Choi C-H, et al (2017) Direct Measurements of Adhesion Forces for Water Droplets in Contact with Smooth and Patterned Polymers. Surf Innov 6:1-52. https://doi.org/10.1680/jsuin.17.00049

835 Tang X, Liu G, Zhang H, et al (2021) Facile preparation of all-cellulose composites from softwood, 836 hardwood, and agricultural straw cellulose by a simple route of partial dissolution. Carbohydr Polym 256:117591. https://doi.org/10.1016/j.carbpol.2020.117591

van Oss CJ (1993) Acid-base interfacial interactions in aqueous media. Colloids Surfaces A Physicochem

van Oss CJ, Chaudhury MK, Good RJ (1988) Interfacial Lifshitz—van der Waals and Polar Interactions in Macroscopic Systems. Chem Rev 88:927-941. https://doi.org/10.1021/cr00088a006

Wang D, Jiang Y, Zhu Z, et al (2020a) Contact Line and Adhesion Force of Droplets on Concentric RingTextured Hydrophobic Surfaces.

Langmuir $36: 2622-2628$.

Wang H, Cao M, Li T, et al (2018) Characterization of the low molar ratio urea-formaldehyde resin with 13C NMR and ESI-MS: Negative effects of the post-added urea on the urea-formaldehyde

Wang J, Wu Y, Cao Y, et al (2020b) Influence of surface roughness on contact angle hysteresis and spreading work. Colloid Polym Sci 298:1107-1112. https://doi.org/10.1007/s00396-020-04680-x

850 Wibowo ES, Lubis MAR, Park B-D, et al (2020a) Converting crystalline thermosetting ureaformaldehyde resins to amorphous polymer using modified nanoclay. J Ind Eng Chem 87:78-89. https://doi.org/10.1016/j.jiec.2020.03.014

Wibowo ES, Park B-D, Causin V (2020b) Hydrogen-Bond-Induced Crystallization in Low-Molar-Ratio Urea-Formaldehyde Resins during Synthesis. Ind Eng Chem Res 59:13095-13104. https://doi.org/10.1021/acs.iecr.0c02268 
856 Wibowo ES, Park B (2021) Crystalline Lamellar Structure of Thermosetting Urea-Formaldehyde Resins at a Low Matio. Macromolecules acs.macromol.1c00073. $858 \quad$ https://doi.org/10.1021/acs.macromol.1c00073

859 Wibowo ES, Park B (2020) Enhancing adhesion of thermosetting urea-formaldehyde resins by preventing 860 the formation of H-bonds with multi-reactive melamine. J Adhes 00:1-29. $861 \quad$ https://doi.org/10.1080/00218464.2020.1830069

862 Wu T, Kummer N, De France KJ, et al (2021) Nanocellulose-lysozyme colloidal gels via electrostatic 863 complexation. Carbohydr Polym 251:1-9. https://doi.org/10.1016/j.carbpol.2020.117021

864 Xu X, Liu F, Jiang L, et al (2013) Cellulose nanocrystals vs. Cellulose nanofibrils: A comparative study 865 on their microstructures and effects as polymer reinforcing agents. ACS Appl Mater Interfaces 5:2999-3009. https://doi.org/10.1021/am302624t

867 Yilgor I, Bilgin S, Isik M, Yilgor E (2012) Tunable wetting of polymer surfaces. Langmuir 28:1480814814. https://doi.org/10.1021/la303180k

869 Yokota S, Kitaoka T, Wariishi H (2007) Surface morphology of cellulose films prepared by spin coating 870 on silicon oxide substrates pretreated with cationic polyelectrolyte. Appl Surf Sci 253:4208-4214. $871 \quad$ https://doi.org/10.1016/j.apsusc.2006.09.037

872 Younesi-Kordkheili H, Kazemi-Najafi S, Eshkiki RB, Pizzi A (2014) Improving urea formaldehyde resin 873 properties by glyoxalated soda bagasse lignin. Eur J Wood Wood Prod 73:77-85. 874 https://doi.org/10.1007/s00107-014-0850-4

875 Zhao Y, Moser C, Lindström ME, et al (2017) Cellulose Nanofibers from Softwood, Hardwood, and 876 Tunicate: Preparation-Structure-Film Performance Interrelation. ACS Appl Mater Interfaces 877 9:13508-13519. https://doi.org/10.1021/acsami.7b01738 

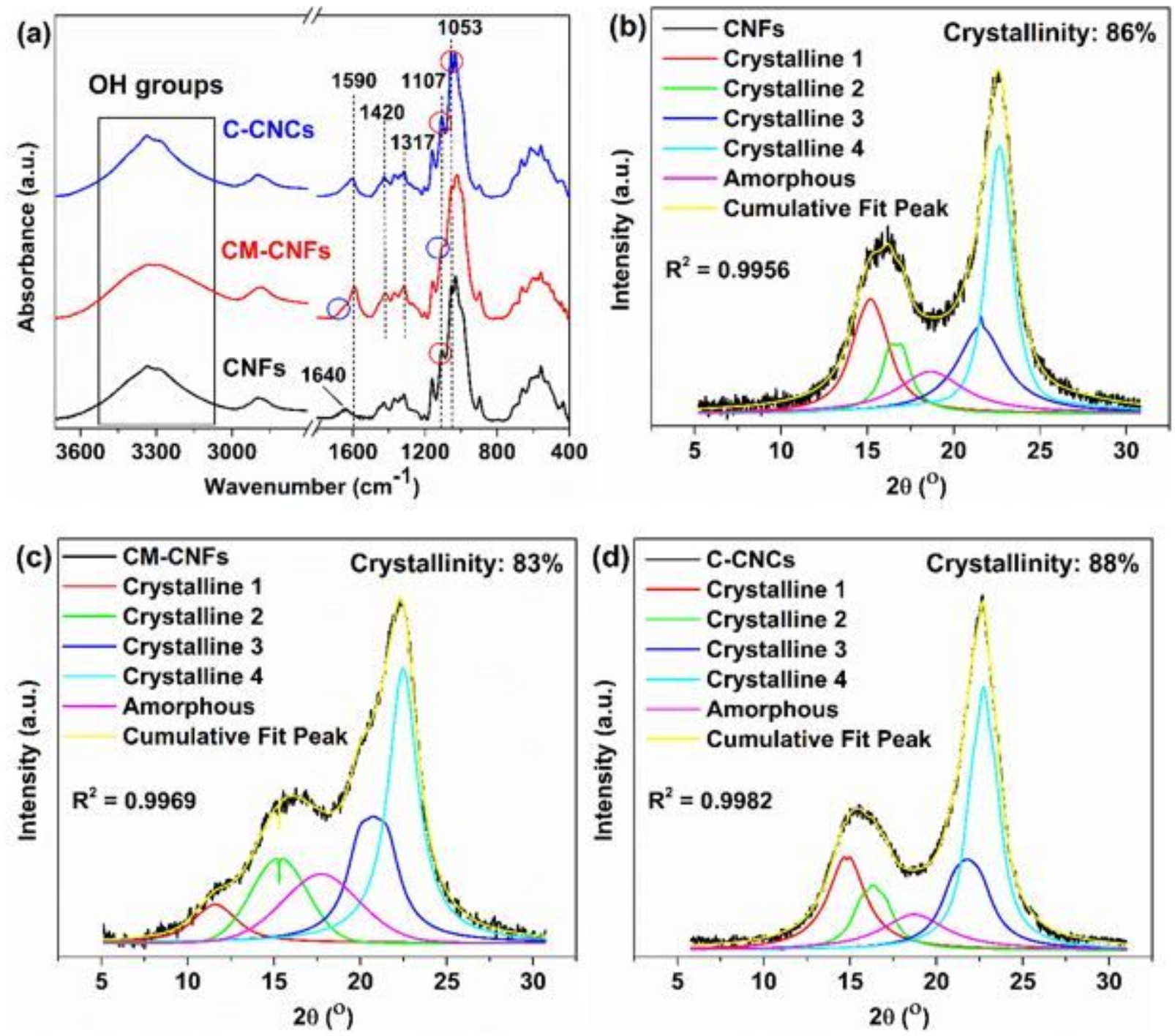

Figure 1

(a) FTIR spectra and deconvoluted XRD patterns of the (b) CNFs, (c) CM-CNFs, and (d) C-CNCs. 


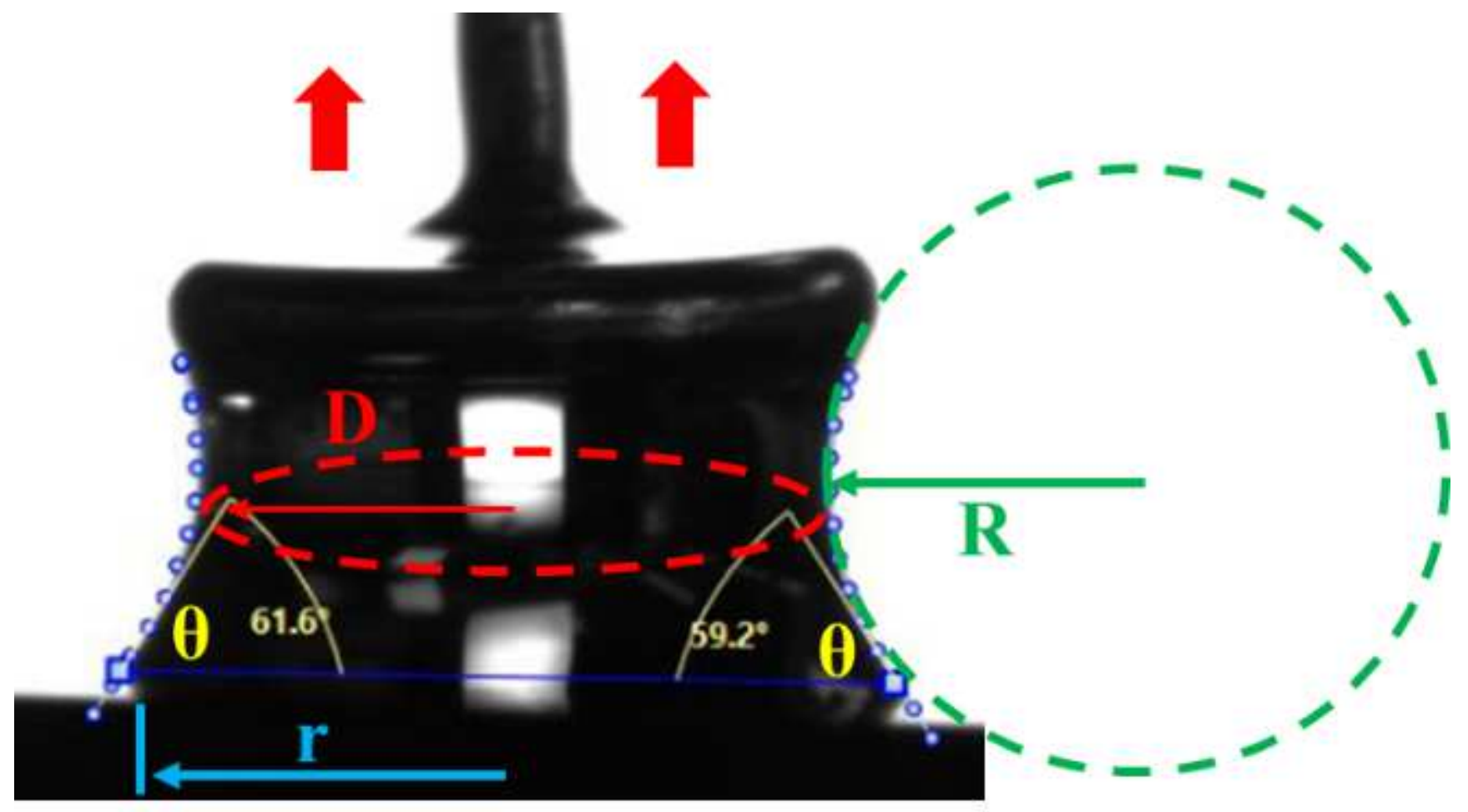

Figure 2

An example of a UF resin droplet in its maximum adhesion state recorded at the retraction stage, where the contact angle $(\theta)$, droplet base radius $(r)$, and principal radii (D and $R$ ) of the droplet are shown. 

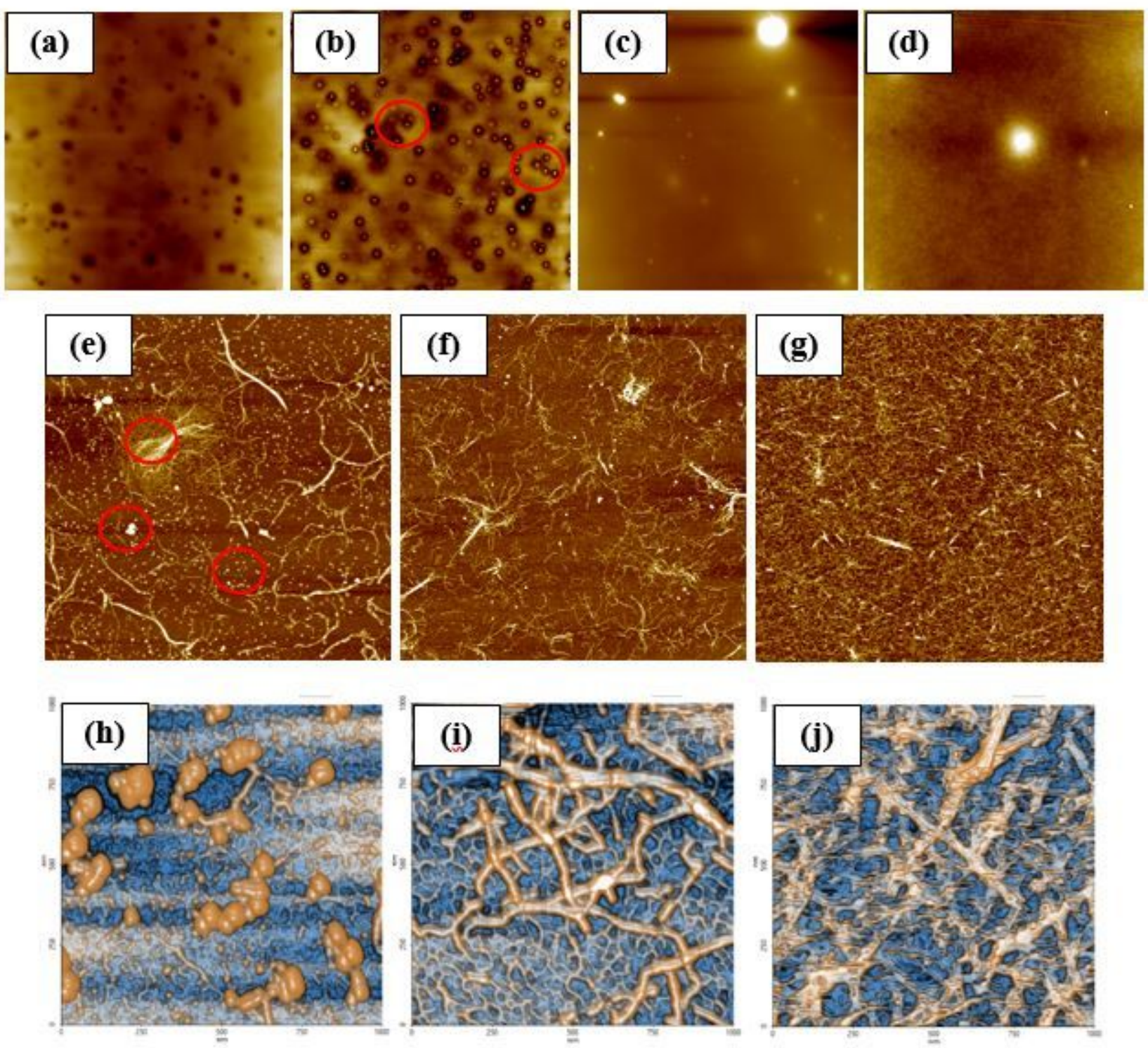

\section{Figure 3}

AFM images $(50 \times 50 \mu \mathrm{m})$ of the films of the cured UF resins with the two molar ratios and hardener contents. (a) 1.0 UF resin, (b) 1.0 UF resin + hardener, (c) 1.6 UF resin, and (d) 1.6 UF resin + hardener. AFM images $(10 \times 10 \mu \mathrm{m})$ of the different nanocellulose films: (e) CNFs, (f) CM-CNFs, and (g) C-CNCs and their color contrast AFM images $(1 \mu \mathrm{m} 2)$ : (h) CNFs, (i) CM-CNFs, and (j) C-CNCs. 


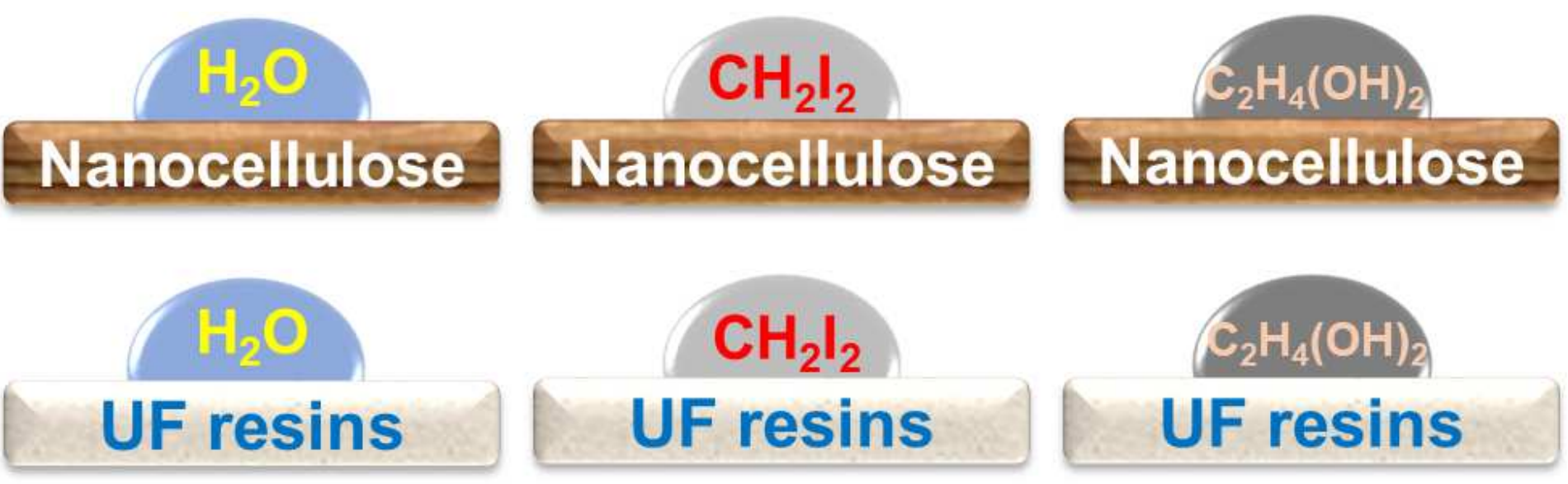

Figure 4

Schematic of the measuring of contact angles on nanocellulose and UF resin films using the probe liquids in the OCG method.
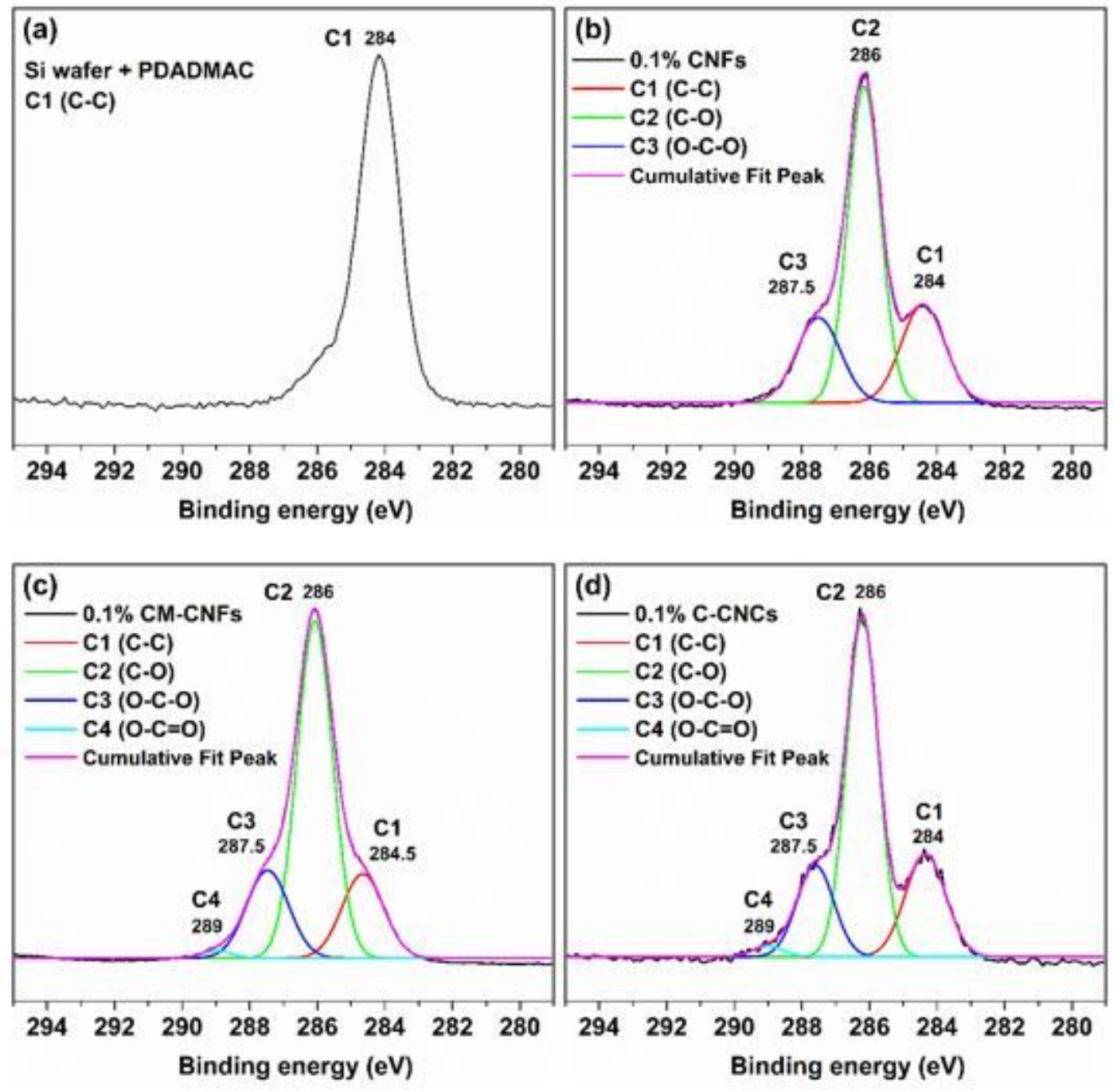

Figure 5 
Deconvolution of the high-resolution C1s XPS spectra of the reference and nanocellulose films. (a) Si wafer + PDADMAC, (b) CNFs, (c) CM-CNFs, and (d) C-CNCs.

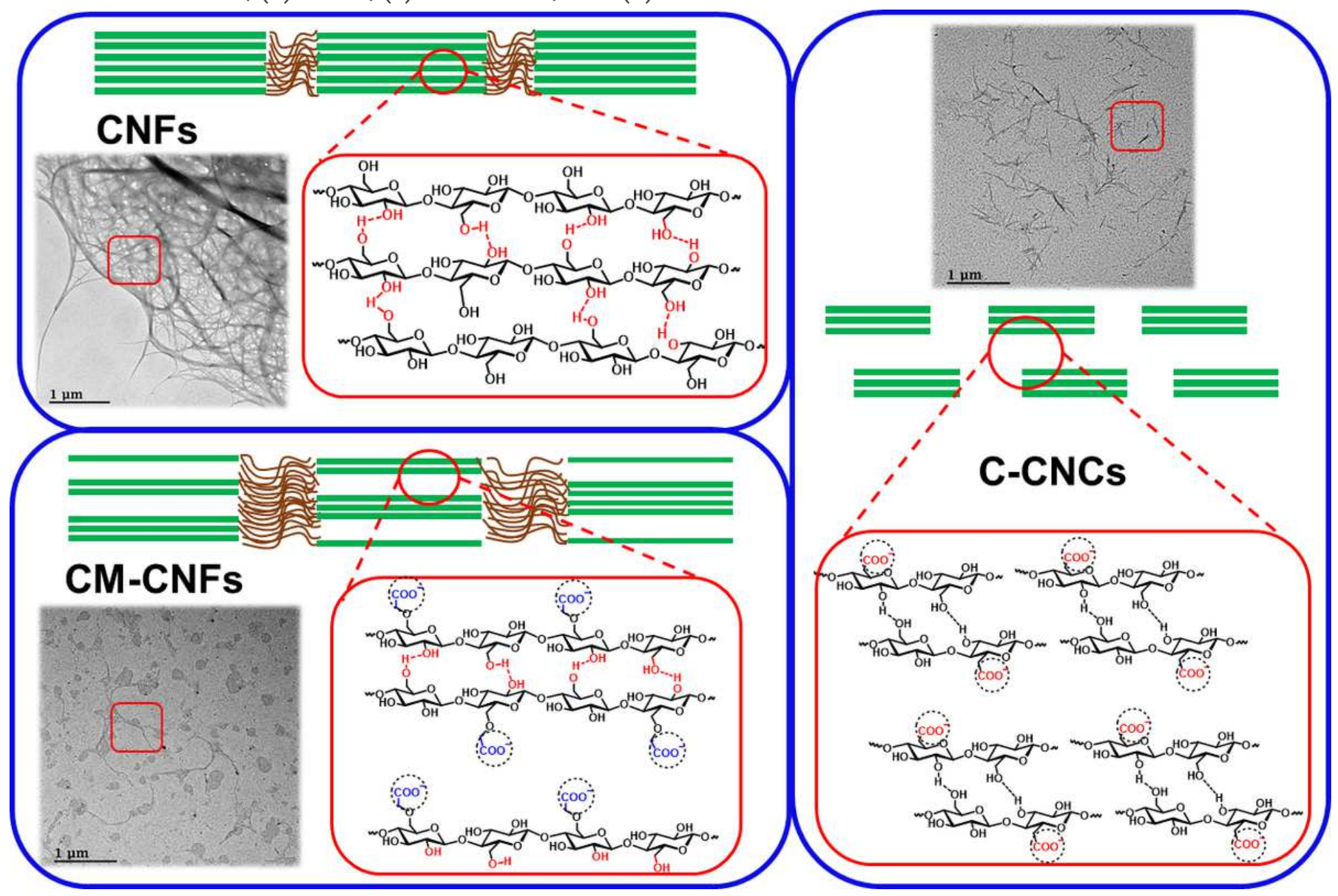

Figure 6

Schematic of the structures of the different nanocellulose samples alongside their actual morphologies shown in the respective TEM images. 

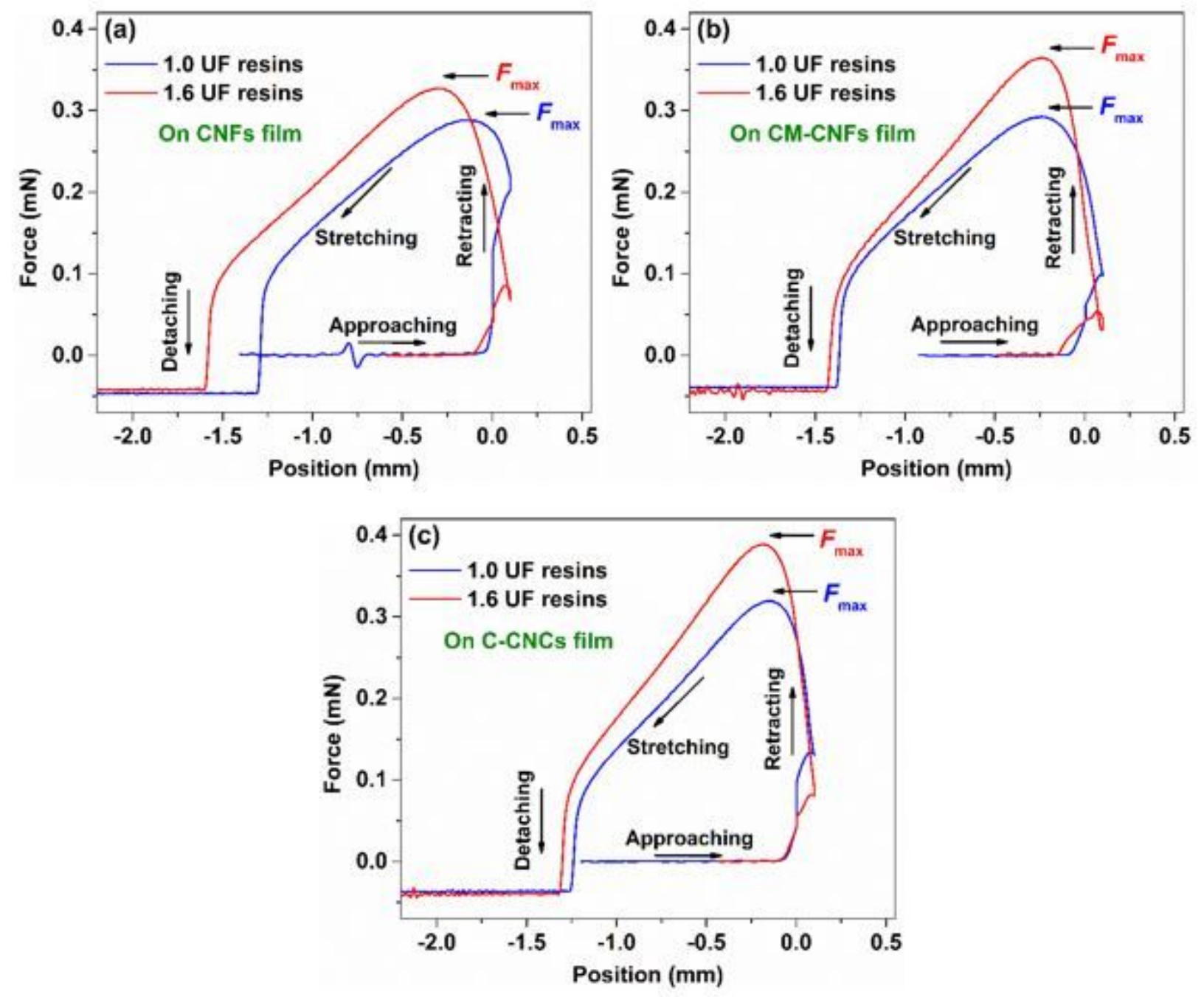

\section{Figure 7}

Typical force-distance curves recorded for the different molar ratios of UF resin droplets on the surfaces of the nanocellulose model films. (a) CNFs, (b) CM-CNFs, and (c) C-CNCs. 


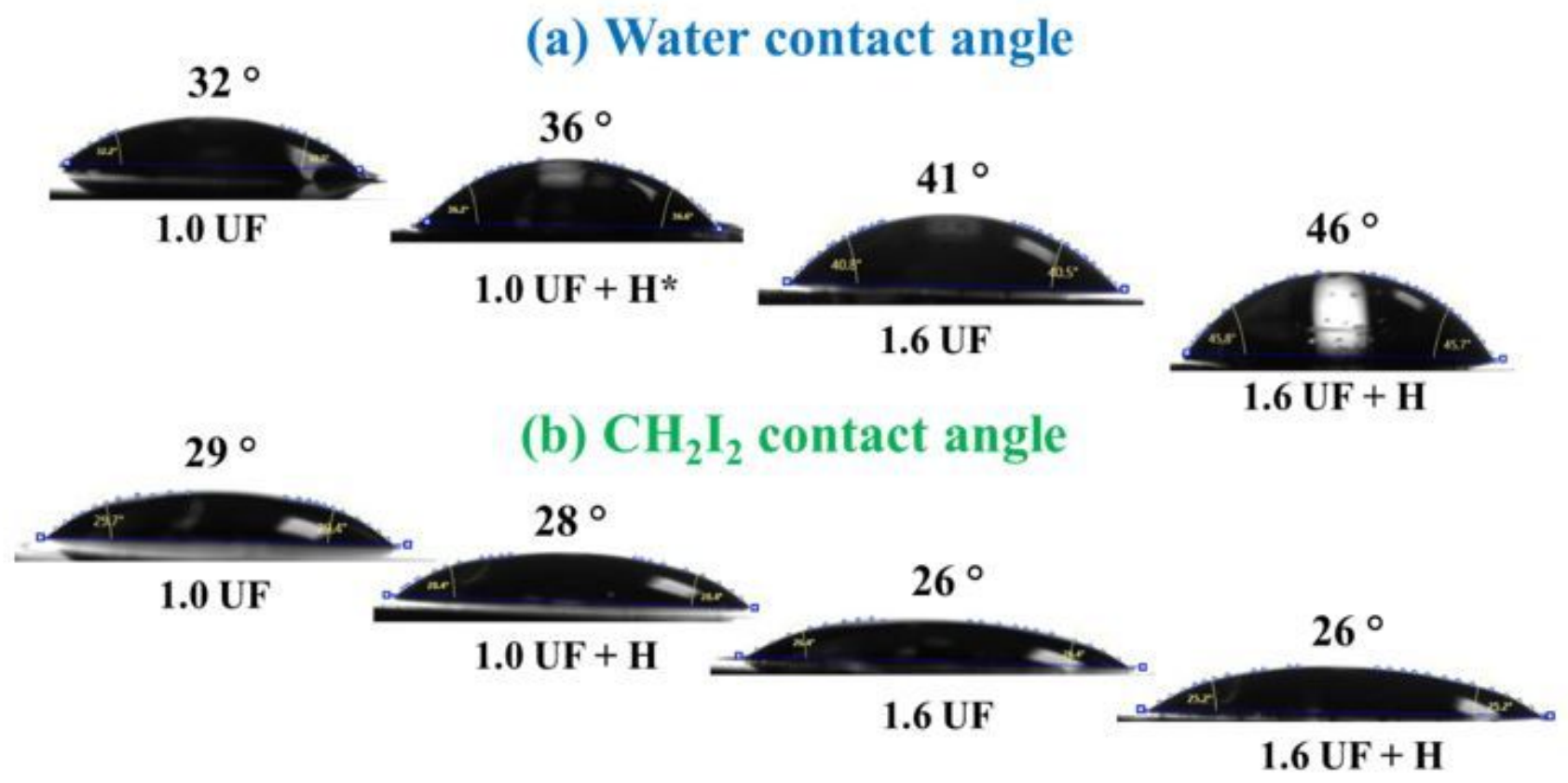

Figure 8

Example of water and diiodomethane contact angle measurements on different UF resins films. ${ }^{*} \mathrm{H}$ indicates that $3 \% \mathrm{NH} 4 \mathrm{Cl}$ was used as a hardener.

\section{Supplementary Files}

This is a list of supplementary files associated with this preprint. Click to download.

- CelluloseSupplementaryinfoSubmitfinal.docx

- GraphicalAbstract.jpg 